\title{
Kaya Modülleri Arasında Farklılıklar: Deriner/Artvin ve Ermenek/Karaman Barajlarından Örnek Çalışmalar
}

\author{
Differences Between Rock Modules: Case Studies From Deriner/Artvin and \\ Ermenek/Karaman Dams \\ Ali KAYABAȘI $I^{\mathfrak{D}}$ \\ Eskişehir Osmangazi Üniversitesi, Jeoloji Mühendisliği Bölümü, 26480 Eskisehir, Turkiye
}

Geliş (Received): 05 Mart (March) 2019 / Düzeltme (Revised): 16 Nisan (April) 2019 / Kabul (Accepted): 22 May1s (May) 2019

\section{$\ddot{\mathbf{O z}}$}

Elastisite modülü ve deformasyon modülü kemer ve beton ağırlıklı baraj projelendirmelerin de girdi parametresi olarak kullanılır. Buna ilave olarak bu modüller kayaç ve kaya kütle sınıflamalarında da kullanılır. Deformasyon modülü ve elastisite modülü kavramları birbirinden farklı olmalarına rağmen uygulamada sıklıkla karıştırılmaktadır. Deformasyon ve elastisite modül değerleri arazi, laboratuvar deneyleri ve jeofizik yöntemlerle belirlenebilmektedir. $\mathrm{Bu}$ çalışmada, Deriner/Artvin ve Ermenek/Karaman baraj yerlerinde yapılan dilatometre ve plaka yükleme deneyleri ve laboratuvar deneyleriyle belirlenen modül değerleri karşılaştırılmıştır. Bu çalışmada ayrıca literatürde karşılaşılan modül karşılaştırmaları da derlenmiş̧tir. Kaya kütle dilatometre deneyi elastisite modülü $\left(\mathrm{E}_{\mathrm{D}}\right)$, kaya kütle plaka yükleme deneyi elastisite modülü $\left(\mathrm{E}_{\mathrm{H}}\right)$, kaya malzemesi statik elastisite modülü $\left(\mathrm{E}_{\mathrm{LS}}\right)$, kaya malzemesi dinamik elastisite modülü $\left(\mathrm{E}_{\mathrm{LD}}\right)$, kaya kütle dilatometre deformasyon modülü $\left(\mathrm{D}_{\mathrm{D}}\right)$, kaya kütle plaka yükleme deneyi deformasyon modülü $\left(\mathrm{D}_{\mathrm{H}}\right)$ gibi modül değerleri arasında regresyon analizleri yapılmıştır. Modül değerlerinin aralarında yapılan regresyon analizleriyle anlamlı yüksek determinasyon katsayılı görgül eşitlikler belirlenmiştir. Bununla birlikte veri sayısının azlığı ve kaya kütle ortamlarının farklı özellikleri olması nedeniyle bu görgül eşitlikler diğer projelerde kullanılmamalıdır veya çapraz adımlı sınamalar yaparak kullanılmalıdır.

Anahtar kelimeler: Deformasyon Modülü, Elastisite Modülü, Deriner Barajı, Ermenek Baraj1, Yerinde Deney

\begin{abstract}
Elasticity modulus and deformation modulus are used an input parameter in arch and concrete dam projects. In addition, these modules are used for the classification of intact rock and rock masses. Although the deformation and elasticity modulus are different from each other, they are often confused in practice. These modules are determined by in-situ tests, laboratory tests and geophysical methods. In this study, the deformation and elasticity modulus determined by dilatometer tests and plate loading tests at Deriner /Artvin and Ermenek /Karaman dam sites and modules obtained by laboratory test results were correlated. The module correlations in literature were compiled as well. Rock mass elasticity modulus $\left(E_{D}\right)$ of dilatometer test, rock mass deformation modulus $\left(D_{D}\right)$ of dilatometer test, rock mass elasticity modulus $\left(E_{H}\right)$ of plate loading test, rock mass deformation modulus $\left(D_{H}\right)$ of plate loading test, intact rock static elasticity modulus $\left(E_{L S D}\right)$ of laboratory tests, intact rock dynamic elasticity modulus $\left(E_{L D}\right)$ of laboratory tests are correlated with regression analysis. Empirical equations obtained by regression analysis performed between rock modulus revealed high determination coefficient. The empirical equations proposed in this study are developed with a number of limited number of data and every rock mass has specific properties. The equations determined in this study should not be used for other projects or a cross check should be performed.
\end{abstract}

Key words: Deformation Modulus, Elasticity Modulus, Deriner Dam, Ermenek Dam, In-situ Test 
Kayabaşı

\section{GíRiş}

$\mathrm{Bu}$ çalışmada Deriner/Artvin ve Ermenek/ Karaman baraj yerlerinde yapılan dilatometre ve plaka yükleme deneyleri gibi yerinde deneyler ile laboratuvarda belirlenen kaya malzemesi modül değerleri karşılaştırılmıştır. Değerlendirmeler sirasında uluslararası yayınlardan derlenen örnekler de sunulmuştur. Deney yöntemlerine göre kaya malzemesi ve kaya kütle modülleri farklılıklar göstermektedir. Bununla birlikte kaya malzemesi modülleri ve kaya kütle modülleri yanlış olarak birbirinin yerine kullanilabilmektedir. Yerinde deneylerle belirlenen kaya kütle modülleri, kaya kütle deformasyon modülü ve kaya kütle elastisite modülü olarak, laboratuvar deneyleriyle belirlenen modüller ise kaya malzemesi statik elastisite modülü olarak bilinir. Bu çalışmada anlatım karmaşası olmaması için belirlendiği deneyin adı modül adı önüne yazılarak aşağıdaki gibi simgelendirilme yapılmıştır; kaya kütle dilatometre deneyi elastisite modülü $\left(\mathrm{E}_{\mathrm{D}}\right)$, kaya kütle plaka yükleme deneyi elastisite modülü $\left(\mathrm{E}_{\mathrm{H}}\right)$, kaya malzemesi statik elastisite modülü $\left(\mathrm{E}_{\mathrm{LS}}\right)$, kaya malzemesi dinamik elastisite modülü $\left(\mathrm{E}_{\mathrm{LD}}\right)$, kaya kütle dilatometre deformasyon modülü $\left(\mathrm{D}_{\mathrm{D}}\right)$, kaya kütle plaka yükleme deneyi deformasyon modülü $\left(\mathrm{D}_{\mathrm{H}}\right)$. Bu çalışma ile modül değerlerinin belirlendiği deney yöntemlerine göre birbirinden farklı değerler ve anlamlar sunduğuna dikkat çekilmeye de çalışılmıştır.

Deriner Baraj1 temelden 249 m gövde yüksekliği ile Türkiyenin en yüksek, dünyanın 6. en yüksek barajıdır. Baraj tipi beton kemerdir. Deriner Baraj1 ve HES, Doğu Karadeniz Bölgesinde Çoruh Nehri üzerinde ve Artvin İl Merkezini Erzurum İl Merkezine bağlayan Devlet Karayolu üzerindeki köprünün $5 \mathrm{~km}$ membasındadır. Ermenek Barajı, temelden 218 metre yüksekliğiyle Deriner Barajı'nın ardından Türkiye'nin en yüksek ikinci barajı unvanını taşır. Ermenek Barajı ve HES, Karaman ilinde Ermenek ilçesinde Göksu Nehri üzerindedir (http://www.dsi.gov.tr/projeler), (Şekil 1).

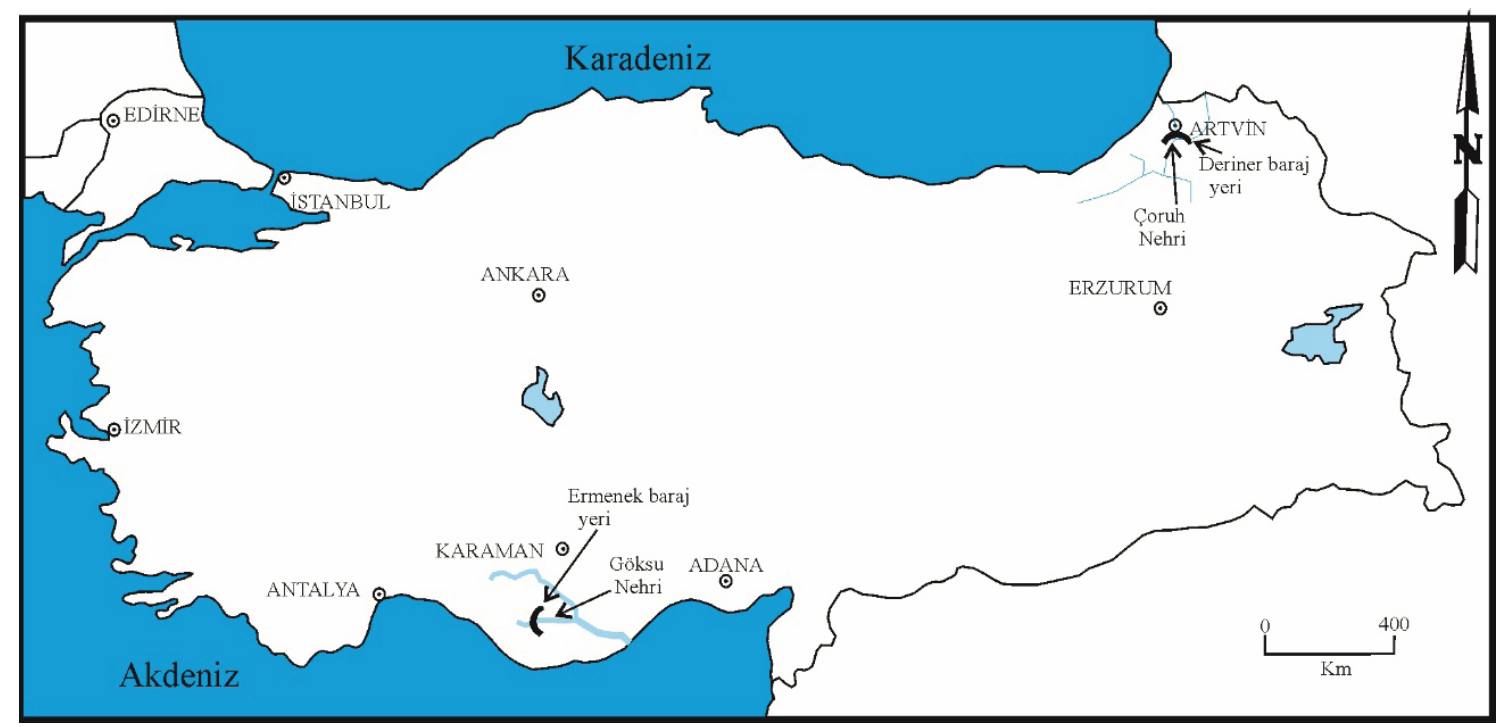

Şekil 1. Deriner ve Ermenek baraj yerleri lokasyon haritası.

Figure 1. Location map of Deriner and Ermenek dam sites. 
Doğay1 oluşturan her malzemenin yük altında kalması ve yükün kalkması, azalması koşullarında başlangıçtaki konumuna geri gelmesi sınırlarına bu malzeme için elastiklik sınırı adı verilir. Mühendislik uygulamalarında gerek kaya ve gerekse de zeminlerin elastiklik sınırlarının belirlenmesi önemli bir araştırma konusu olmuştur. Eksenel yükleme-deformasyon eğrisinin doğrusal kısmının eğimine "Young modülü" diğer bir deyişle "elastisite modülü” adı verilir (ISRM, 1978). Laboratuvarda yapılabilen tek eksenli sıkışma dayanımı deneyinde Young modülünün belirlenmesi değişik ölçüm yöntemleriyle, teğet (tanjant) modülü, kiriş (sekant) modülü ve ortalama modül gibi isimler almıştır (Şekil 2).
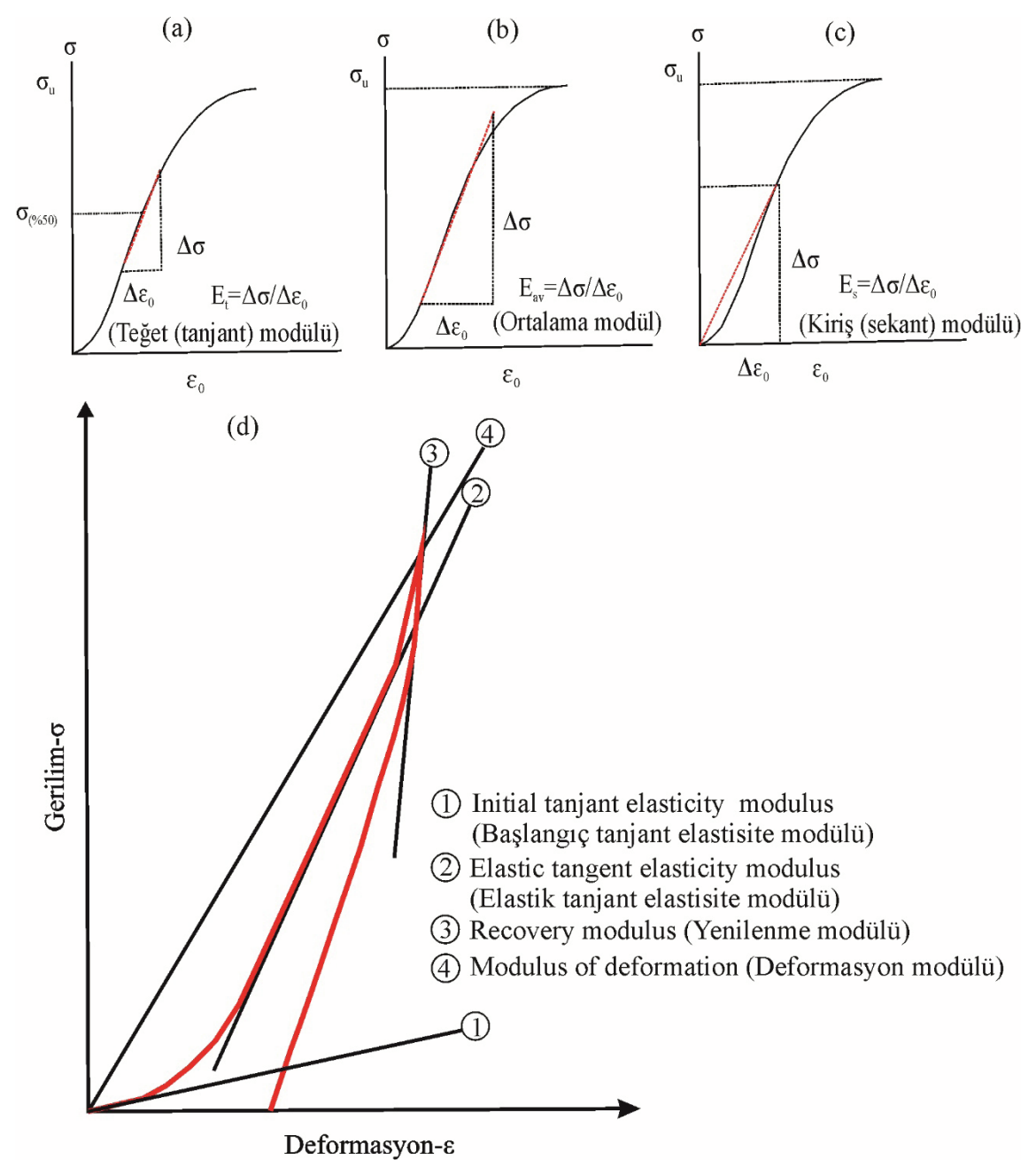

Şekil 2. Modüllerin belirlenmesi a) kaya malzemesi teğet (tanjant modülü) b) kaya malzemesi ortalama modül c) kaya malzemesi kiriş (sekant modülü) (ISRM, 1978) d) Kaya kütlesinde tek eksenli yükleme-boşaltma döngüsünden belirlenen modüller (Hoek ve Diederichs, 2006).

Figure 2. Determination of modules a) tangent modulus of intact rock specimen, b) average modulus of intact rock specimen, c) secant modulus of intact rock specimen, (ISRM, 1978) d) rock mass modules from obtained from single loading-unloading cycle (Hoek and Diederichs, 2006). 
Kayabaşı

Deneyler sırasında kaya kütle üzerine k1sa sürede uygulanan gerilim-deformasyon değerleri, uzun süreli değişen/değişmeyen gerilim değerleri altında kalacak bir baraj yapısı için yeterli olmayacaktır. Bu nedenle kaya kütlenin uzun süreli olarak proje yükleri altında birakılarak deforme olmasinın beklenmesi ve deformasyonların belirlenmesi olanağı, yerinde deneylerin avantajlarından birisidir.

Palmstrom ve Sigh (2001) yerinde deneylerden oluşturulan gerilim-deformasyon modülü değerlerinin nasıl hesaplanacağını göstermiştir. Yükleme-boşaltma döngülerine çizilen teğetin eğimi deformasyon modülünü verirken, yükleme-boşaltma döngülerinin her birinin doğrusal kısımlarının eğimi elastisite modülü değerini vermektedir. Şekil 3'te görüldüğü gibi, uygulanan gerilim aralığ1 değerinin, Wd deformasyon aralığı değerine oran1 deformasyon modülünü verir. Uygulanan gerilim aralığ 1 değerinin, We deformasyon aralığ 1 değerine oranı ise elastisite modülüdür.

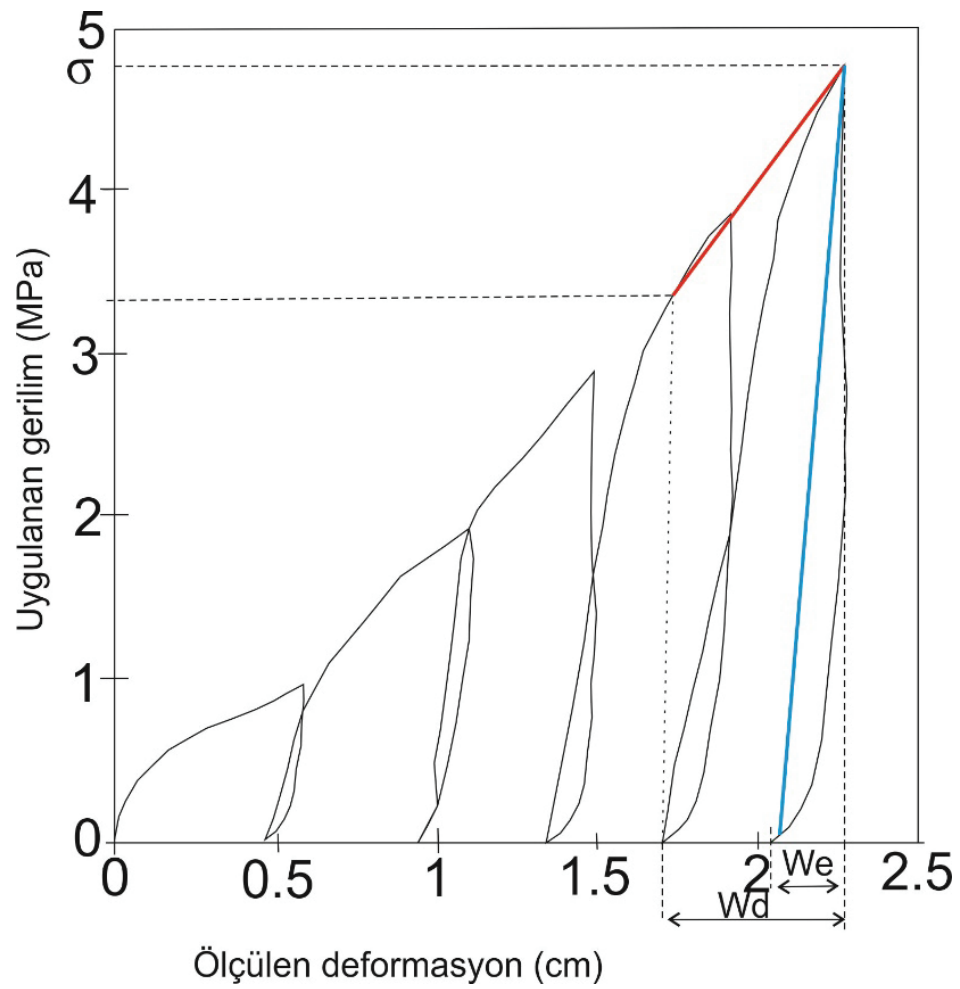

Şekil 3. Yükleme-boşaltma döngülerinden kaya kütle deformasyon modülünün ve elastisite modülünün belirlenmesi (Palmstrom ve Singh, 2001).

Figure 3. Rock mass deformation modulus and elasticity modulus determined by loading-unloading cycles (Palmstrom and Singh, 2001). 
Laboratuvar ortamında sonik hız deneyi (ulratrasonik dalga hızları kullanılarak dinamik elastisite modülünün tayini) yardımıyla kaya malzemesi dinamik modül değerleri belirlenebilmektedir. Kaya malzemesi modülleri $\mathrm{E}_{\mathrm{LD}}$ ile $\mathrm{E}_{\mathrm{LS}}$ 'nin karşılaştırılması ve aralarındaki farklılıklar pekçok araştırmanın konusu olmuştur (Al-Shayea, 2004; Ciccoti ve Mulargia, 2004; Song vd., 2004; Christaras vd., 1994; Gue'gen ve Palciauskas, 1994). Bozunma derecesinin artmasıyla, $E_{L S}$ değerinin düşmesiyle, $E_{L D}$ ve $E_{L S}$ değerleri arasındaki farkın arttığı belirlenmiştir (Gue'guen ve Palciauskas, 1994; Al-Shayea, 2004).

Sonik hız deneyinde AX çaplı (31 mm) ve daha büyük örnekler üzerinde $V_{p}$ ve $V_{s}$ yayılma hızları belirlendikten sonra aşağıdaki eşitlik kullanılarak dinamik young modülü $\left(\mathrm{E}_{\mathrm{LD}}\right)$ belirlenir (ASTM D2845, 2008).

Dinamik Young modülü $(P a): E_{L D}=\rho V_{s}^{2} \frac{\left(3 V_{p}^{2}-4 V_{s}^{2}\right)}{\left(V_{p}^{2}-V_{s}^{2}\right)}$

Kaya kütleleri üzerinde yapılan yapıların oluşturacağ1 yükün, kaya kütlesinin elastik sınırları içerisinde olması önemlidir. Bu sınırlar üzerinde yapılan yüklemelerde yapılarda aşırı oturma ve taşıma gücü sorunları ortaya çıkar. Yapıların temelini oluşturan kaya kütlelerinin farklı modüllere sahip olması da yapıda farklı oturmalara ve deformasyonlara sebep olabilir. Özellikle kemer tipi barajlarda temel kaya kütlesinin farklı modül değerlerine sahip olması, baraj gövdesi için risk oluşturmaktadır. Kaya kütlesinin deformasyon modülü ile baraj gövdesinde kullanılan betonun elastisite modülü arasındaki oran, beton gövdede oluşacak gerilimlerin değerinde belirleyicidir. Beton deformasyon modülü ile kaya kütle deformasyon modülü oranının tüm baraj ekseni boyunca sabit olması tercih edilir. Kullanılacak betonunun modül değeri ile temeli oluşturan kaya kütlesinin modül değeri oranının 16 ve üstünde olması, barajın deformabilitesinin taban kaya kütlesi tarafından belirlendiğini göstermektedir. $\mathrm{Bu}$ oranın 4 ve altına düşmesi durumunda temel kayasının deformabilite üzerindeki etkisinin gittikçe azaldığı görülmüştür. Kullanılacak beton modül değeri ile yapı yükünü taşıyacak olan kaya kütle modül değeri arasındaki etkileşim sadece beton barajlar için değil diğer jeoteknik uygulamalarda da geçerlidir (örneğin köprü ayakları, yüksek binalar) (Wyllie, 1992).

Gerek laboratuvar ve gerekse yerinde deneylerinin yapılması ayrıntılı bir hassasiyet gerektirmektedir. Laboratuvar ve yerinde deneyleri ile kayaç ve kaya kütle özelliklerinin gerçekçibir şekilde belirlenebilmesiiçin yeterince tecrübeli teknisyen, cihazların standartlara göre üretilmesi, cihaz kalibrasyonlarının doğru yapılmas1, uygulanan deney programlarının ilgili standartlara uygun olarak yapılması gibi koşullar vardır. $\mathrm{Bu}$ koşulların yeterince sağlanamaması nedeniyle, $\mathrm{mm}$ ölçeğinde alınan deformasyonlardaki hatalar tüm sonuçları etkileyebilecektir. Yerinde deneylerin yapılacağ1 kaya ortamında yapılan patlatma işleminin kaya kütlenin özelliklerine etkisi olmaktadır. Palmstrom ve Singh (2001) plaka kriko (PJT), plaka yükleme (PLT) ve Goodman kriko deneylerinin uygulanmasında patlatma kaynaklı dezavantajları çalışmışlardır (Şekil 4). Araştırmacılar galerilerde yapılan plaka yükleme deneyi verilerinin patlatma etkisialtında olduğunu ve düşük veriler belirlendiğini tespit etmiş, en sağlıklı ölçümün PJT ile extensometreler ile patlatmadan etkilenen seviyelerden alınmasını önermişlerdir. 
Kayabaşı

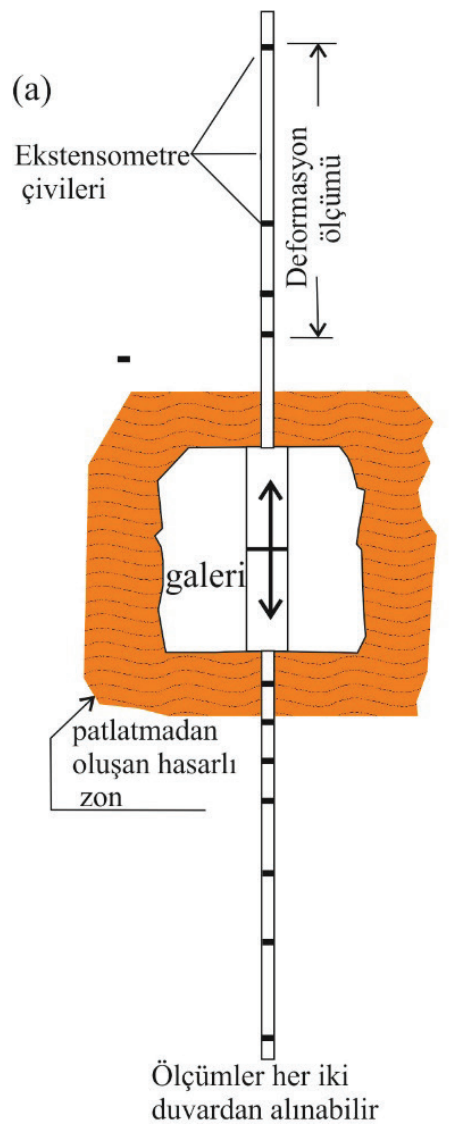

(b)

(c)
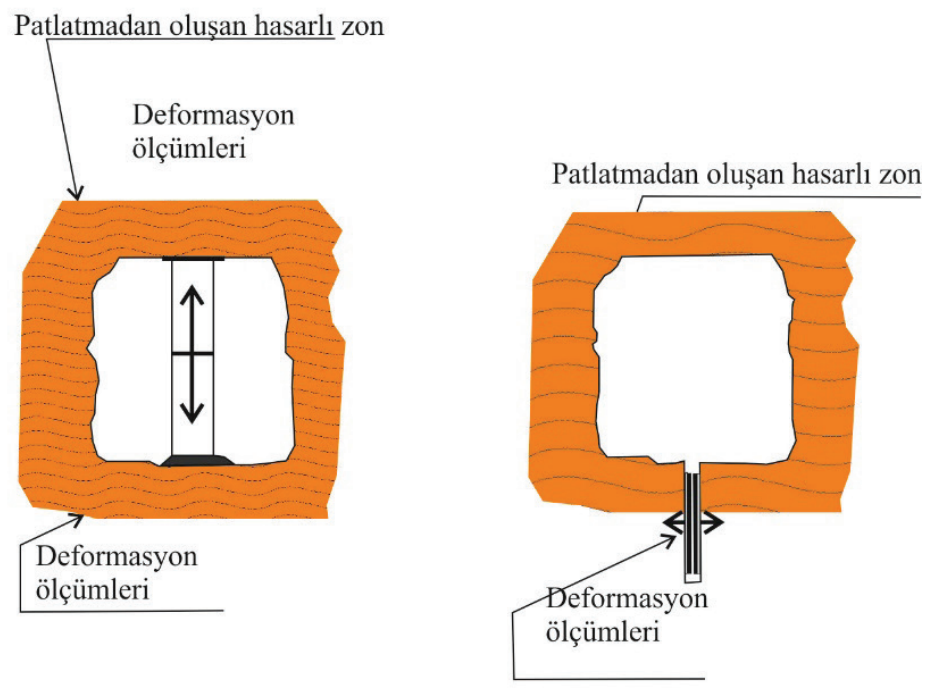

Ölçümler her iki duvardan alınabilir

Ölçümler her iki duvardanve tavandan alınabilir

Şekil 4. a) Plaka Kriko Deneyi (PJT) b) Plaka Yükleme Deneyi (PLT) c) Goodman Kriko Deneyi .

Figure 4. a) Plate Jacking Test (PJT) b) Plate Loading Test (PLT) c) Goodman Jacking Test.

\section{ÖNCEKİ ÇALIŞMALAR}

Jeoteknik çalışmalardan belirlenen modüller arasındaki ilişkileri tespit etmek araştırmacıların üzerine düştüğü bir konu olmuştur. Kujundzíc ve Grujíc (1966)'da Yugoslavya'da kireçtaşlarında yapılan baraj etütlerinde belirlenen yerinde modül değerleri için genelleştirilmiş Eşitlik 2'yi önermişlerdir. Şekil 5a'da ise yerinde deformasyon modülü $\left(\mathrm{D}_{\mathrm{H}}\right)$ ve yerinde elastisite modülü $\left(\mathrm{E}_{\mathrm{H}}\right)$ değerlerinin belirlenişini göstermişlerdir. Burada $\mathrm{E}_{\mathrm{H}}$ boşaltma eğrilerinin eğiminden belirlenmiştir. Toplam deformasyon en yüksek yükleme seviyesinden belirlenmektedir. Gerilim seviyesine bağlı olarak $D_{H}$ değeri değişebilirken $\mathrm{E}_{\mathrm{H}}$ değeri sabit kabul edilebilir. Bu nedenle $\mathrm{E}_{\mathrm{H}}>\mathrm{D}_{\mathrm{H}}$ eşitsizliğinin farklılığı gerilim seviyesine bağlı olarak değişebilir. $E_{H}$ ve $D_{H}$ arasındaki farklılık Şekil $5 b$ ve $5 c$ 'de net olarak görülmektedir. En geniş eşitsizlik aralığı 1.5 ile 2.5 arasında değişmektedir. 

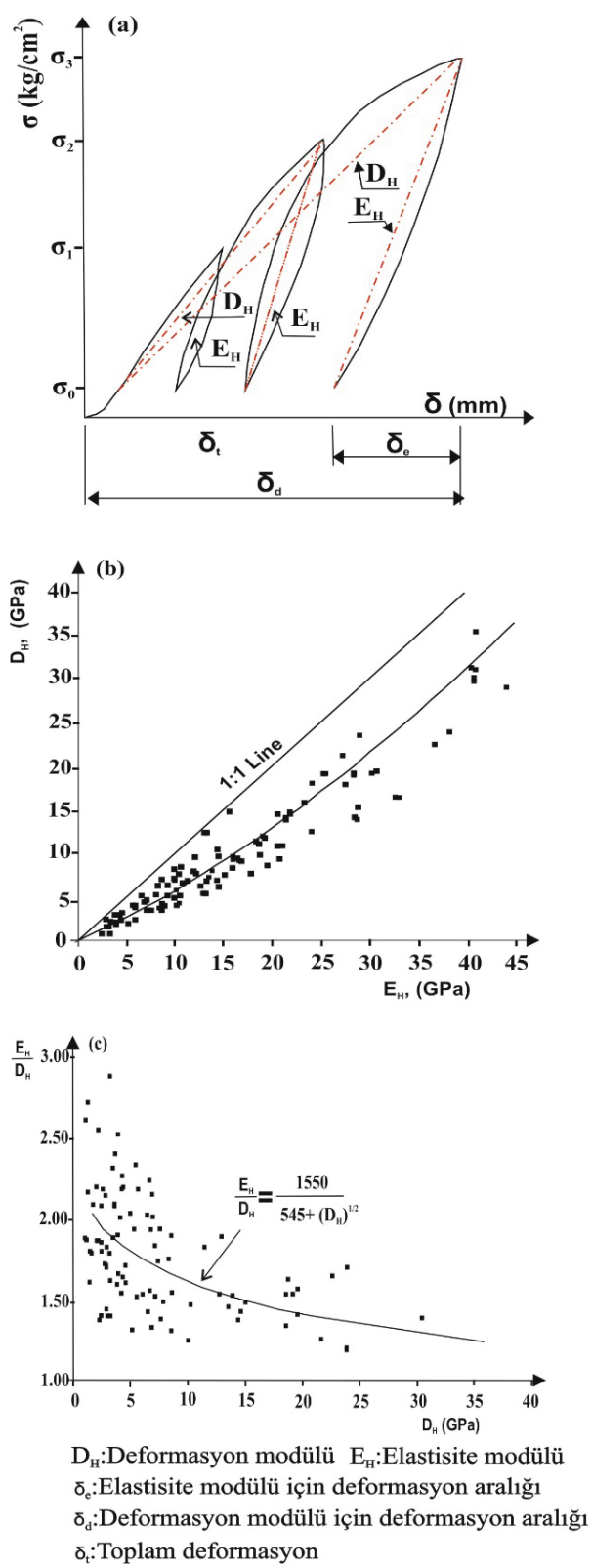

Şekil 5. a) Yugoslavya'da kireçtaşlarında yapılan örnek yükleme-boşaltma deneyi b) $\mathrm{D}_{\mathrm{H}}-\mathrm{E}_{\mathrm{H}}$ modüllerinin karşılaştırılması c) $\mathrm{E}_{\mathrm{H}} / \mathrm{D}_{\mathrm{H}}-\mathrm{D}_{\mathrm{H}}$ grafiği (Kujundzíc ve Grujíc, 1966).

Figure 5. a) A sample loading-unloading test performed on Yugoslavia limestones b) comparison of $D_{H}-E_{H}$ modules c) $E_{H} / D_{H}-D_{H}$ graph (Kujundzic and Grujic, 1966).

$$
E_{H} \approx \frac{15.50 D_{H}}{6.45 \sqrt{D_{H}}}
$$

Eşitlik 2'den görüleceği gibi $\mathrm{D}_{\mathrm{H}}$ değerinin 5 ve $50 \mathrm{GPa}$ arasinda olmasi durumunda $\mathrm{E}_{\mathrm{H}}$ değerinin 8.9 ve $57.5 \mathrm{GPa}$ olduğunu görürüz. $\mathrm{E}_{\mathrm{H}}$ ve $\mathrm{D}_{\mathrm{H}}$ değerlerinin farklılığının küçük değerlerde daha fazla olduğu görülmektedir. Bunun nedeni kaya kütlesinde var olan süreksizliklerin ve ayrışmanın yükleme ve boşaltma eğrilerine etkisinden kaynaklanmaktadır.

Bieniawski (1978) Güney Afrika Orange Nehri projelerinde yapılan plaka yükleme deneylerinden belirlenen $\mathrm{D}_{\mathrm{H}}$ değerleri ile aynı seviyelerden alınan örneklerden laboratuvarda belirlenen $\mathrm{E}_{\mathrm{LS}}$ değerlerini karşılaştırmıştır (Şekil 6). Dört ayrı kaya kütlesinde yapılan yerinde deneyler ile laboratuvar deneylerinden belirlenen modül değerleri arasında anlamlı bir bağıntı belirlenememiştir, $\mathrm{E}_{\mathrm{LS}}$ modülleri plaka yükleme deneylerinden belirlenen $D_{H}$ modüllerinden büyük olarak belirlenmiştir.

Kulhawy ve Goodman (1980)'de kaya kütle deformasyon modülünün belirlenmesine yönelik Eşitlik 3'ü önermiştir

$\mathrm{D}=\mathrm{j} \mathrm{E}_{\mathrm{LS}}$

Burada D:kaya kütle deformasyon modülü, j:ortalama süreksizlik aralığı, $E_{L S}$ : sağlam kaya elastisite modülünü ifade etmektedir.

Galera vd. (2005) Fransa'da Penthus tünelinin açıldığı şişt kaya kütlesinde plaka yükleme deneyi yapmıştır. Çalışmalarından örnek olarak verdikleri plaka yükleme deneyi grafiğinde $\mathrm{E}_{\mathrm{H}} / \mathrm{D}_{\mathrm{H}} \approx 7$ değerine ulaşmaktadır (Şekil 7). 
Kayabaşı

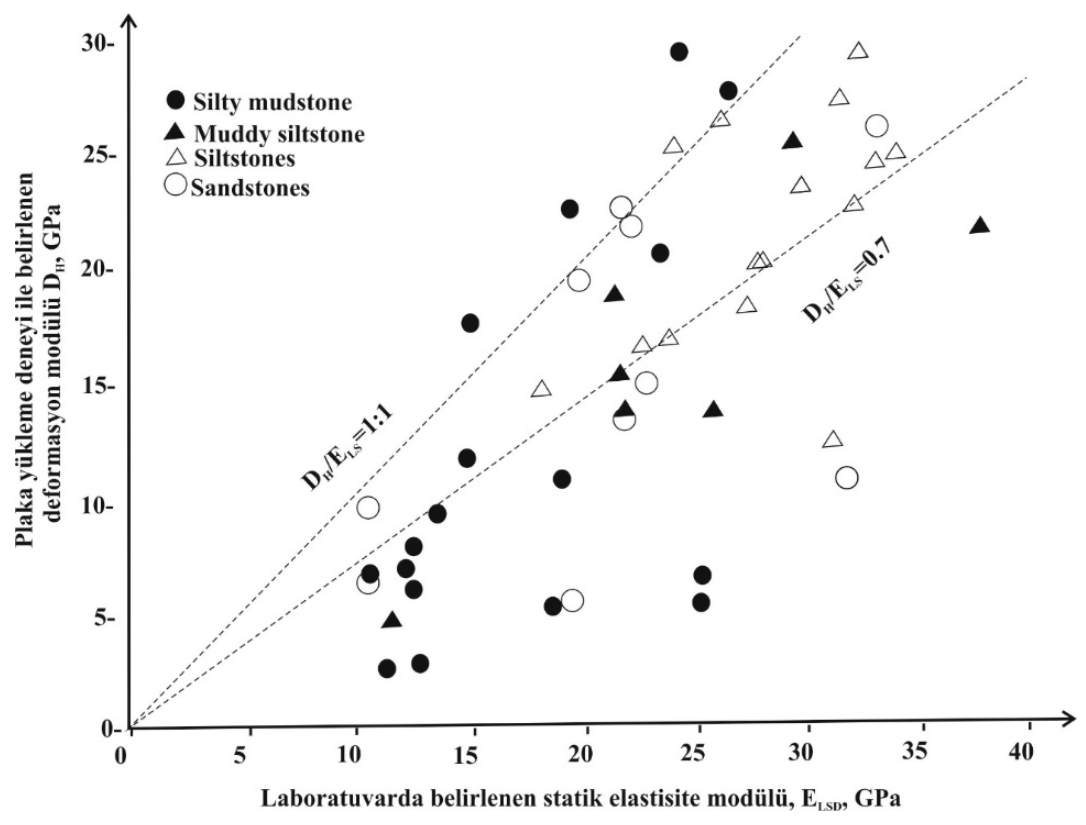

Şekil 6. Plaka yükleme deneyi ile belirlenen deformasyon modülü $\left(\mathrm{D}_{\mathrm{H}}\right)$ ile laboratuvarda belirlenen statik elastisite modülünün $\left(\mathrm{E}_{\mathrm{LS}}\right)$ karşılaştırılması (Bieniawski, 1978).

Figure 6. Comparison of the deformation modulus $\left(D_{H}\right)$ determined by plate loading test and the static elasticity modulus $\left(E_{L S}\right)$ determined by laboratory tests (Bieniawski, 1978).

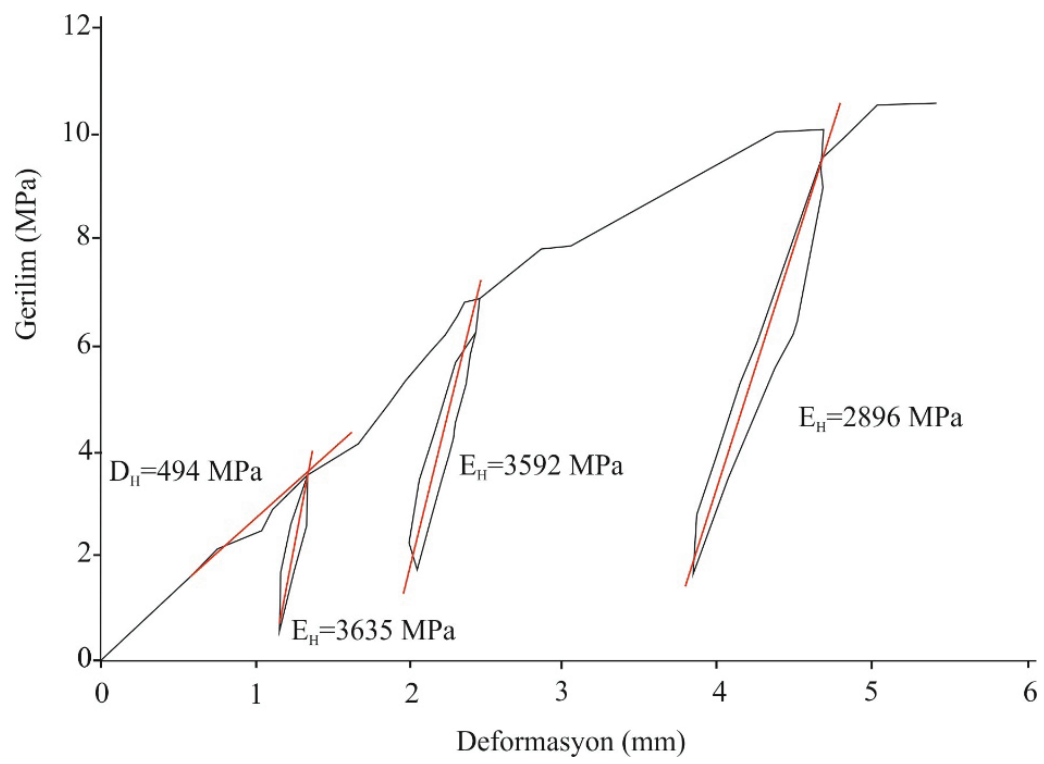

Şekil 7. Penthus tünelinin (Fransa) açıldığı şistlerde yapılan bir plaka yükleme deneyi grafiği (Galera vd., 2005).

Figure 7. A plate loading test graph carried out on schist rock mass of Penthus tunnel (France) (Galera et al., 2005). 
Munır (2006), Pakistan'daki Indus nehri üzerinde Khyber Pahktunkhwa bölgesinde projelendirilen Basha barajı etütlerinde yaptığ1 doktora tezi çalışmalarında kaya sınıflama sistemleri ile deformasyon modüllerini karşılaştırmıştır. Baraj yeri mafik intrüsiflerden dioritlerden oluşmaktadır. Diorit kaya kütlesi açık renkli, çok yüksek dayanımlı ve masiftir. $\mathrm{Bu}$ tez çalışmasında Basha baraj sahasında plaka yükleme deneylerinden belirlenen yerinde deformasyon modülleri $\left(\mathrm{D}_{\mathrm{H}}\right)$ ile yerinde deneylerin yapıldığ 1 litolojilerden alınan kayaç örneklerinden laboratuvarda belirlenen elastisite modülleri $\left(\mathrm{E}_{\mathrm{LS}}\right)$ karşılaştırılmıştır. $\mathrm{E}_{\mathrm{LS}}$ değerleri ile $\mathrm{D}_{\mathrm{H}}$ arasındaki ortalama modül oranı 0.55 olarak belirlenmiştir. $\mathrm{E}_{\mathrm{LS}}$ değeri devamlı olarak $\mathrm{D}_{\mathrm{H}}$ değerinden yüksek çıkmıştır. Şekil 8'de görüldüğü gibi $\mathrm{E}_{\mathrm{LS}}-\mathrm{D}_{\mathrm{H}}$ arasında logaritmik bir ilişki ile determinasyon katsayısı $\mathrm{R}^{2}=0.91$ olarak belirlenmiştir.

Martínez vd. (2012) bozunmuş ve bozunmamış on ayrı kireçtaşında kaya malzemesi dinamik elastisite modülü $\left(\mathrm{E}_{\mathrm{LD}}\right)$ ve kaya malzemesi elastisite modüllerini $\left(E_{L S}\right)$ belirlemişlerdir. Şekil 9'da $E_{L D}$ ile $E_{L S}$ değerlerinin karş1laştırma grafiği verilmiştir. Her iki değer arasında zayıf bir ilişki vardır. 1:1 çizgisi $\mathrm{E}_{\mathrm{LD}} / \mathrm{E}_{\mathrm{LS}}$ değerinin 1 olduğu konumu ifade eder.

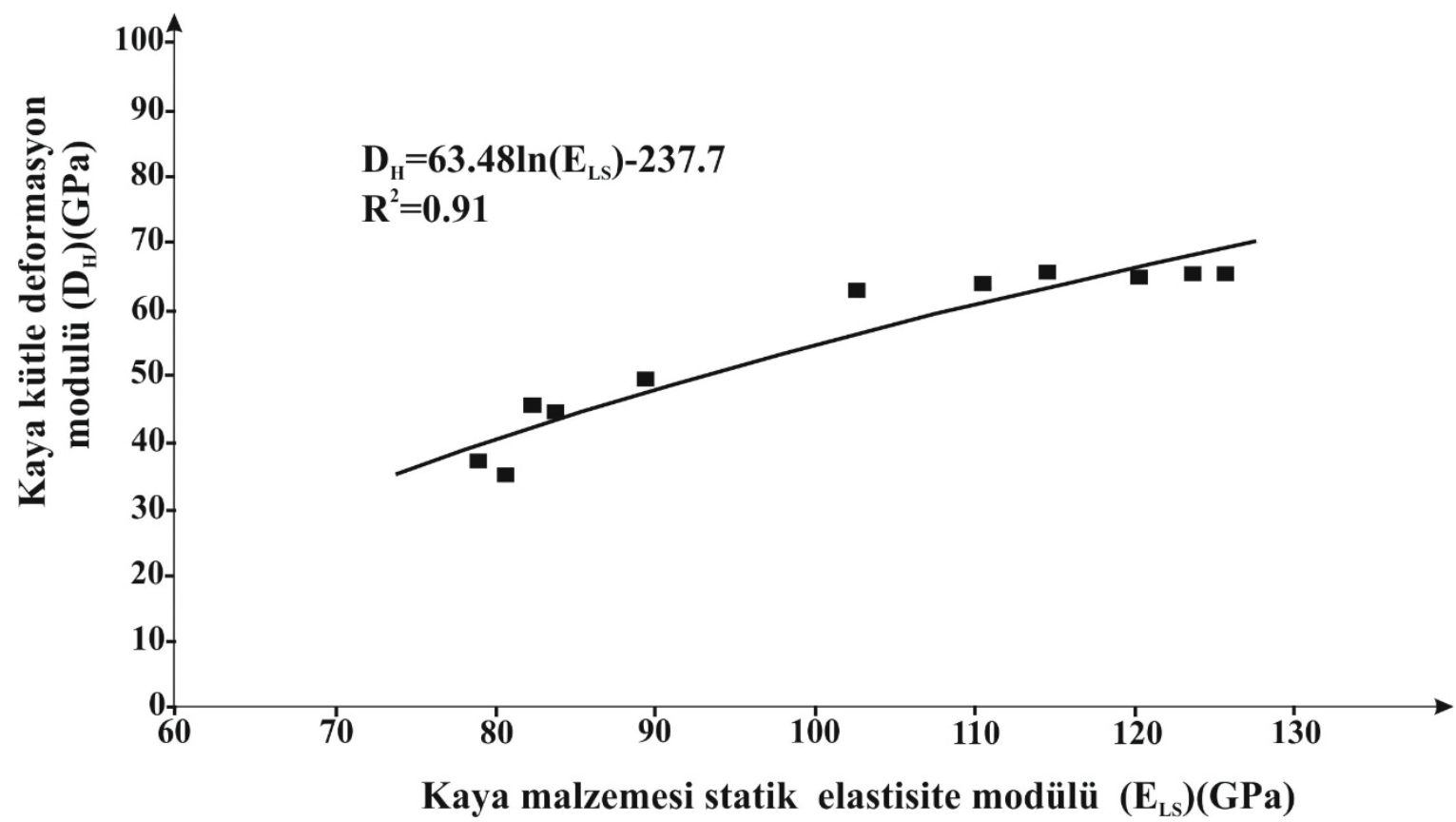

Şekil 8. Kaya kütle deformasyon modülü $\left(\mathrm{D}_{\mathrm{H}}\right)$-kaya malzemesi statik elastisite modülü $\left(\mathrm{E}_{\mathrm{LS}}\right)$ arasında yapılan regresyon analizi grafiği (Munır, 2006).

Figure 8 . The regression analysis graph of the rock mass deformation modulus $\left(D_{H}\right)$ and the intact rock elasticity modulus $\left(E_{L S}\right)$ (Munir, 2006). 
Kayabaşı

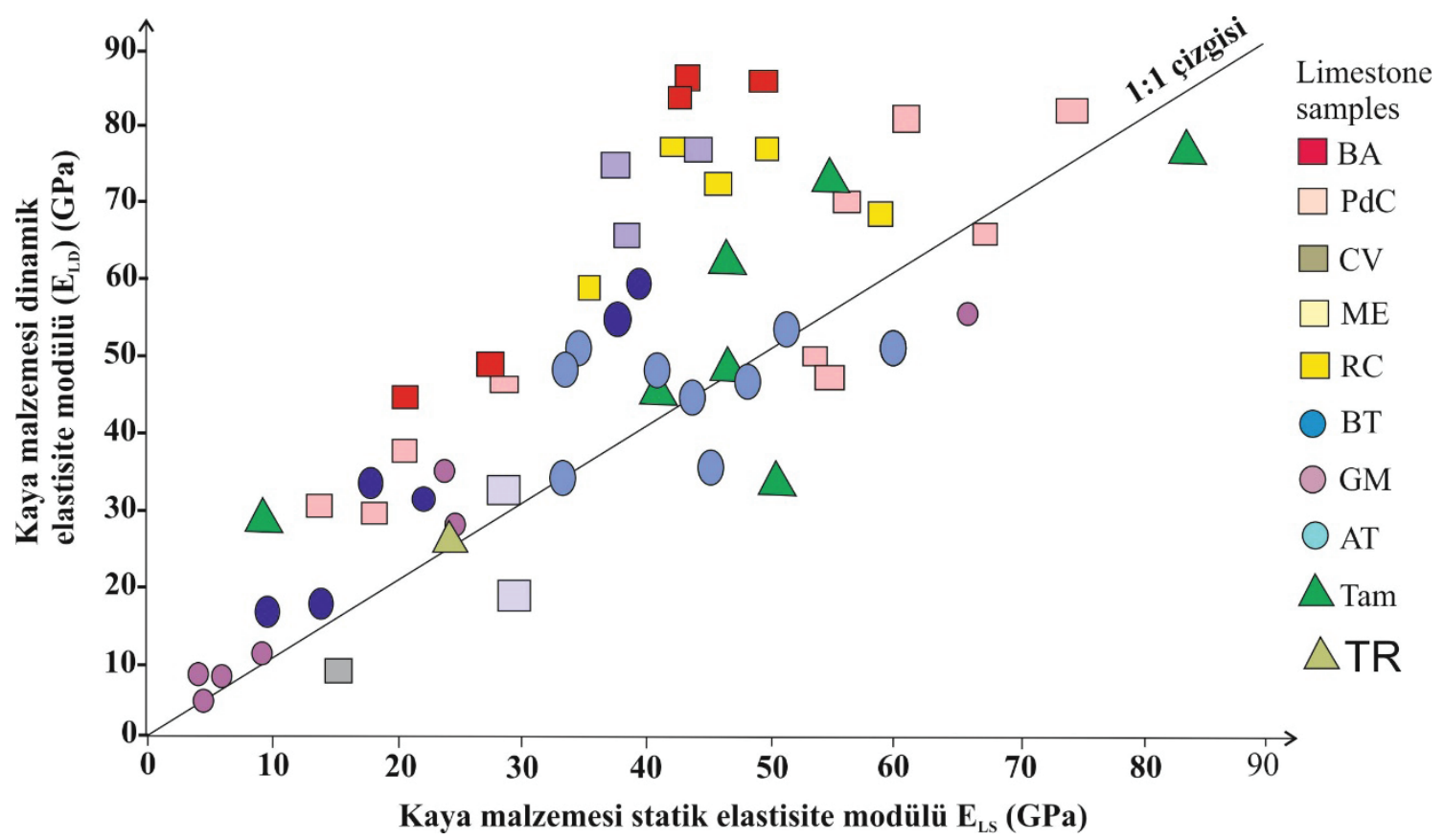

Şekil 9. Kaya malzemesi dinamik elastisite modülü $\left(\mathrm{E}_{\mathrm{LD}}\right)$ kaya malzemesi ile statik elastisite modülü $\left(\mathrm{E}_{\mathrm{LS}}\right)$ arasında yapılan regresyon analizi grafiği (Martínez vd., 2012).

Figure 9. The regression analysis graph between the intact rock dynamic modulus $\left(E_{L D}\right)$ and the intact rock static elasticity modulus $\left(E_{L S}\right)$ (Martínez et al., 2012).

$E_{L D}=\rho_{b u l k} V_{p}^{2} \frac{(1-2 \gamma)(1+\gamma)}{(1-\gamma)}$

Araştırmacılar $\mathrm{E}_{\mathrm{LD}}$ değerini Eşitlik 4'ten belirlemiştir. Burada $\rho=$ bulk yoğunluk, $V p=P$ dalgası hızı, v: poisson oranıdır.

$$
E_{L S}=\frac{1}{K} \rho_{b u l k} V_{p}^{2} \frac{(1-2 \gamma)(1+\gamma)}{(1-\gamma)}
$$

$\mathrm{E}_{\mathrm{LD}} / \mathrm{E}_{\mathrm{LS}}=\mathrm{K}$ katsayıs1 ile tanımlanmas1 durumunda olarak ifade edilmiştir. $\mathrm{K}>1$ olması durumunda $E_{L D}$ değeri gerçek değerinden fazla tahmin edilirken, $\mathrm{K}<1$ olması durumunda $\mathrm{E}_{\mathrm{LD}}$ gerçek değerinden az tahmin edilir. Bu çalışmada K katsayısı 0.5 ile 2.1 arasında belirlenmiştir. Ciccotti ve Mulargia (2004) K katsayısının 1-1.3 arasinda belirlerken, Al-Shayea (2004) ise K katsayısını 0.85-1.86 arasında olmasını ifade etmişlerdir.

Brotons vd. (2014) değişik sicaklıkta 1sıtılan sedimanter kayaçların dinamik ve statik modülleri arasında iki analitik görgül ilişki geliştirmişlerdir. Araştırmacılar aynı zamanda bu konuda daha önce önerilen görgül eşitliklerin performansını da test etmişlerdir. Geliştirilen bu görgül eşitlikler ile İspanya'nın Alicante șehirindeki bulunan tarihi binaların yapımında kullanılan San Juliáns taşlarının dinamik elastisite modülü değerinden statik elastisite modülü değerini tahmin etmişlerdir. $\mathrm{Bu}$ yöntemle tarihi yapılardan karot almayarak, yapılara zarar vermemişlerdir. Araştırmacılar, $\mathrm{K}$ katsayısının $\left(\mathrm{E}_{\mathrm{LD}} / \mathrm{E}_{\mathrm{LS}}\right)$ yüksek modüllü kayaçlarda bire yaklaştığını ifade etmiştir. Düşük 
modüllü kayaçlarda K katsayısının birden fazla olabileceğini bunun nedeninin ise statik elastisite modülünün hacim, oryantasyon ve çatlakların dağılımından etkilendiğini, dinamik elastisite modülünün bu tür fiziksel özelliklere karş1 düşük hassasiyette olmasından kaynaklandığını belirtmişlerdir.

\section{DERINER/ARTVIN VE ERMENEK/ KARAMAN BARAJ YERLERINDEN ÖRNEKLER}

\section{Deriner (Artvin) Barajı Plaka Yükleme Deneyi Çalışmaları}

Deriner Barajı ve çevresi gri, pembemsi kuvarsdiyoritlerden oluşur. ISRM (1981)'e göre süreksizlik aralığı orta ve geniştir. Süreksizlik açıklıkları ise kapalı veya kısmen açıktır. Süreksizlik açıklıklarında kuvars dolgu vardır. Süreksizlik yüzeyleri genelde pürüzlü ve az ayrışmıştır. Deriner Barajı araştırmalarında açılan galerilerde 48 adet galeri içi plaka yükleme deneyi (Narin vd., 1986) ve bu galeriler içinde açılan sondaj kuyularında 23 adet Oyo 200 dilatometresi deneyi yapılmıştır (Kaya ve Kayabaş1, 1992), (Şekil 10).

Plaka yükleme deneyi, ortalama kesitli galeriler içerisinde anizotropi etkisini azaltmak için deney galerisinin eksenine paralel ya da dik olacak şekilde yatay ve düşey yönde yükleme uygulanarak yapılmıştır (ASTM D4394, 2017). $\mathrm{Bu}$ çalışmada deneyde uygulanan yükler " $\mathrm{MPa}$ ve oluşan deformasyonlar "mm" cinsinden belirlenmiştir. Yüklemeler sırasında, $0.5 \mathrm{MPa}$ 'lık bir yükleme 1 dakika süresince verilmiş ve bunu takip eden süre sonunda okumalar alınmıştır. Aynı şekilde 2 dakikalık zaman sürecinde yük düşürülerek okuma yapılmıştır. Maksimum gerilim 6.5 $\mathrm{MPa}$ olarak alınmıştır. Deneyler yatay ve düşey yönlü yapılmıştır. Deformasyon ölçümleri her plaka çevresindeki 3 adet deformasyon göstergesi tarafından alınmıştır (Şekil 11).

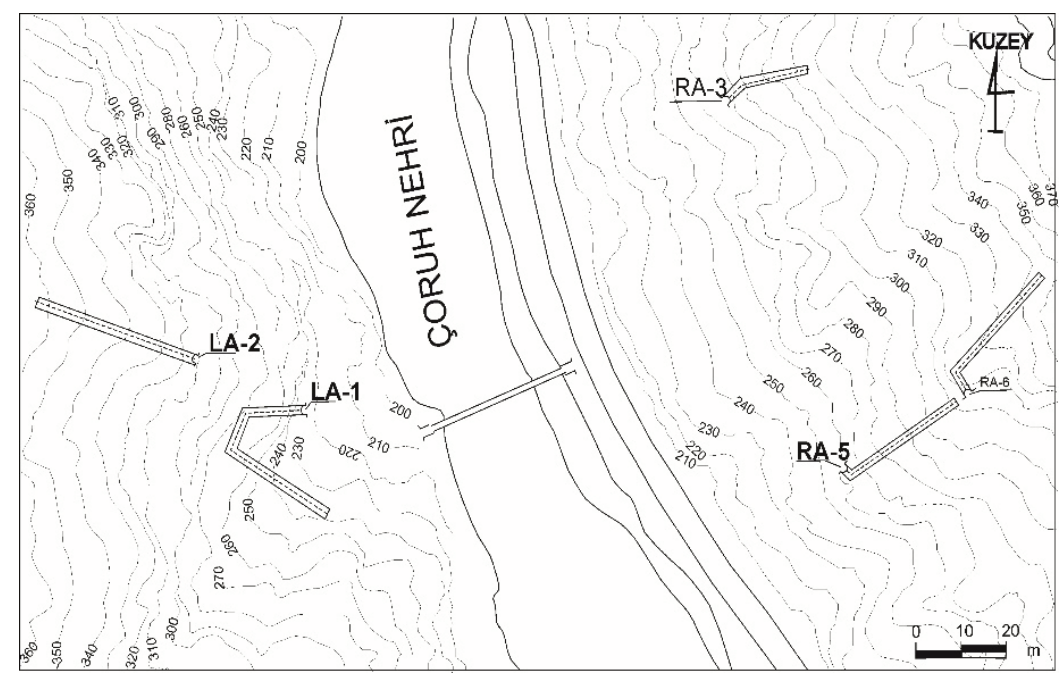

Şekil 10. Deriner (Artvin) baraj yeri galeri lokasyon haritası.

Figure 10. Location map of galleries at the Deriner (Artvin) dam site. 
Kayabaşı

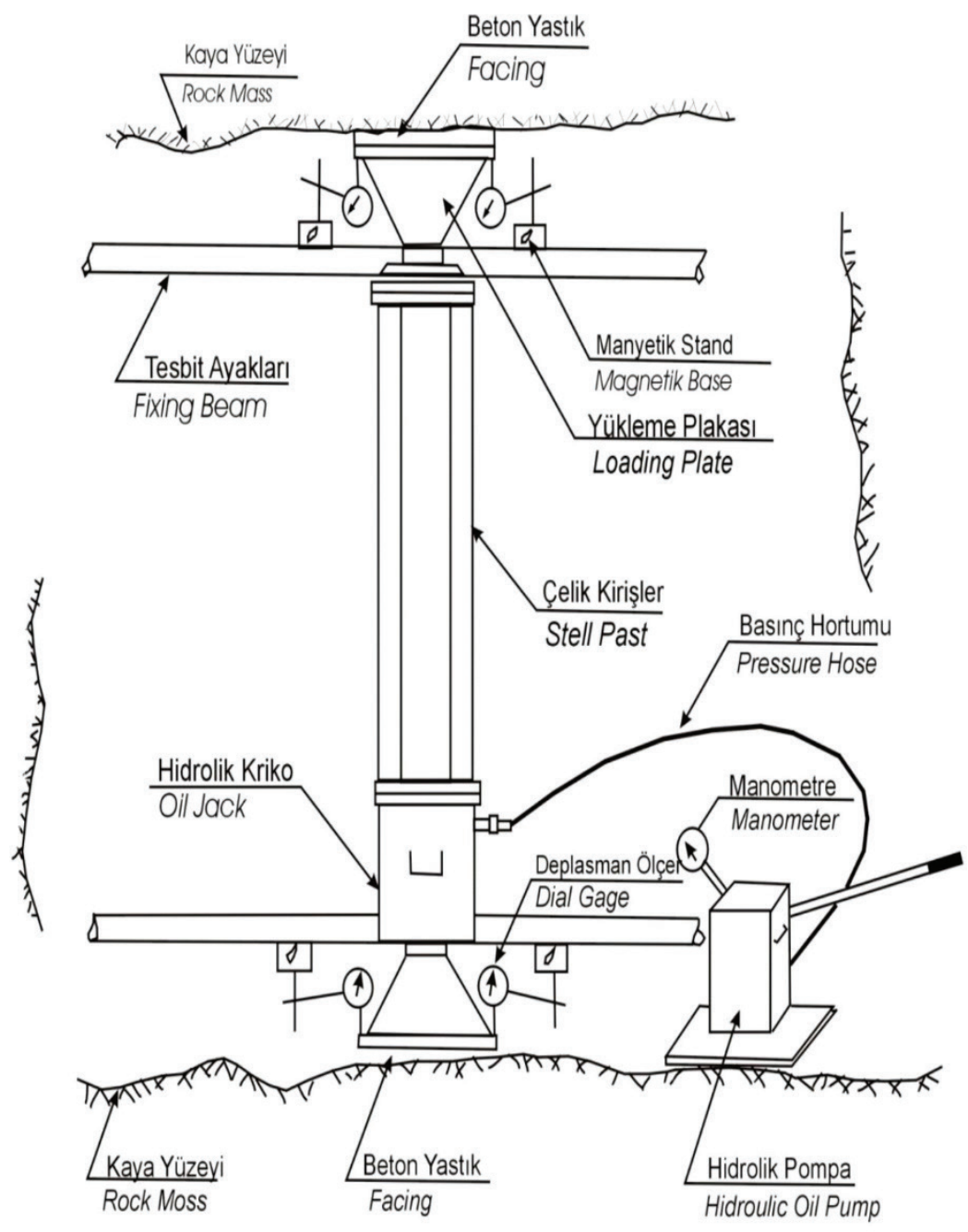

Şekil 11. Düşey yönlü plaka yükleme deneyi şematik görünümü (EİE-122, 1992).

Figure 11. Schematic view of vertical plate loading test (EIE-122, 1992).

Galeri içerisinde plaka yükleme deneyi için değişik deney programları vardır. Yükleme- zaman uygulamaları zemine bir program dahilinde uygulanmıştır (Şekil 12). 


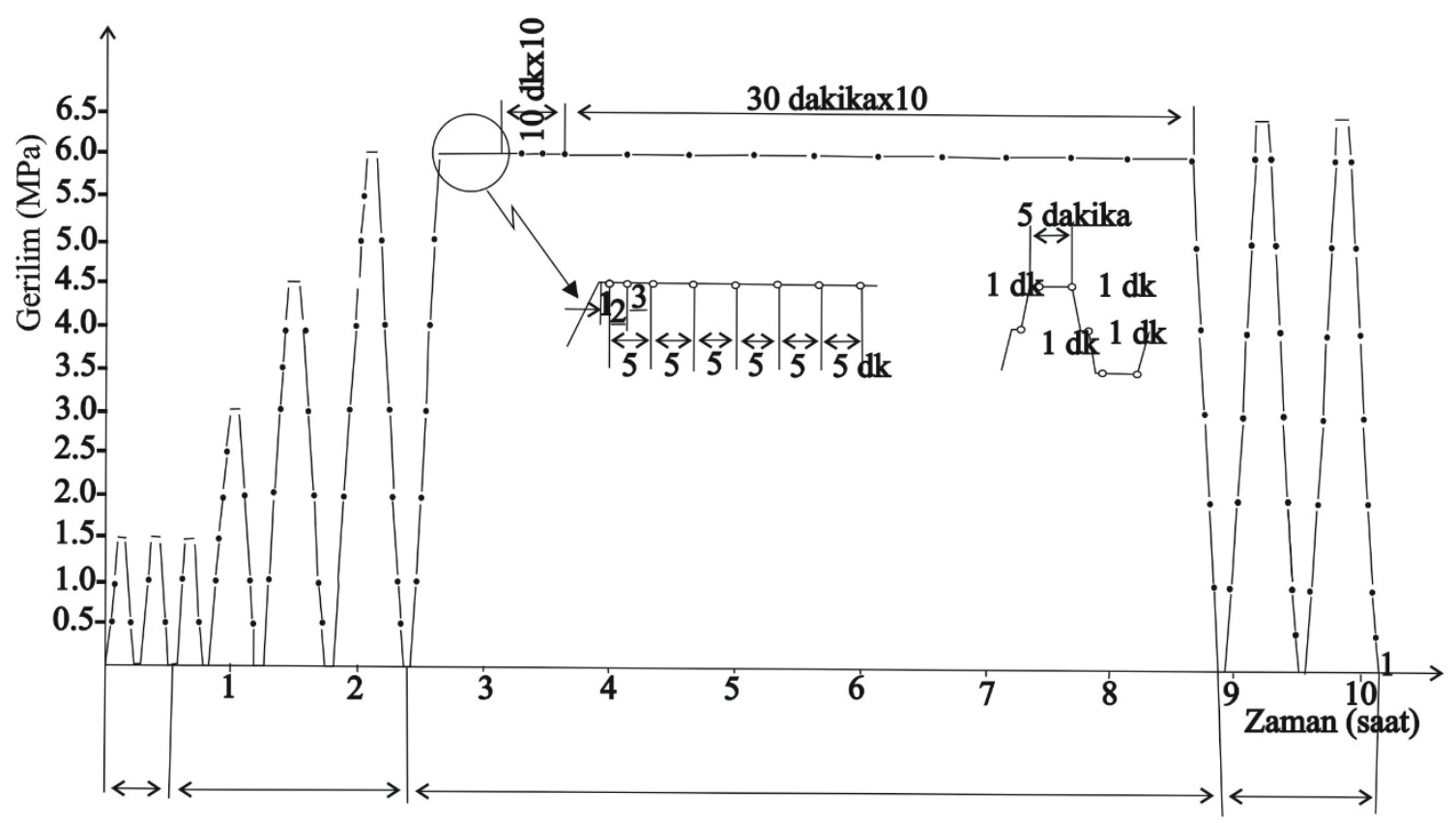

Şekil 12. Plaka yükleme deneyi için gerilim-zaman programı (Narin vd., 1986).

Figure 12. Stress-time program for plate loading test (Narin et al., 1986).

Deney sonunda oluşan deformasyon-basınç ve zaman-deformasyon grafikleri üzerinden şematik olarak da gösterilen toplam deformasyon $(\delta)$, elastik deformasyon $(\delta \mathrm{e})$, plastik deformasyon $(\delta \mathrm{p})$, kümülatif toplam deformasyon $(\Sigma \delta)$, kümülatif plastik deformasyon $(\Sigma \delta \mathrm{p})$ ve akma deformasyonu $(\delta c)$, deformasyon modülü $\left(D_{H}\right)$, tanjant elastisite modülü $\left(\mathrm{E}_{\mathrm{t}}\right)$ ve sekant elastisite modülü ( $\left.\mathrm{E}_{\mathrm{s}}\right)$ hesaplanır (Şekil 13).
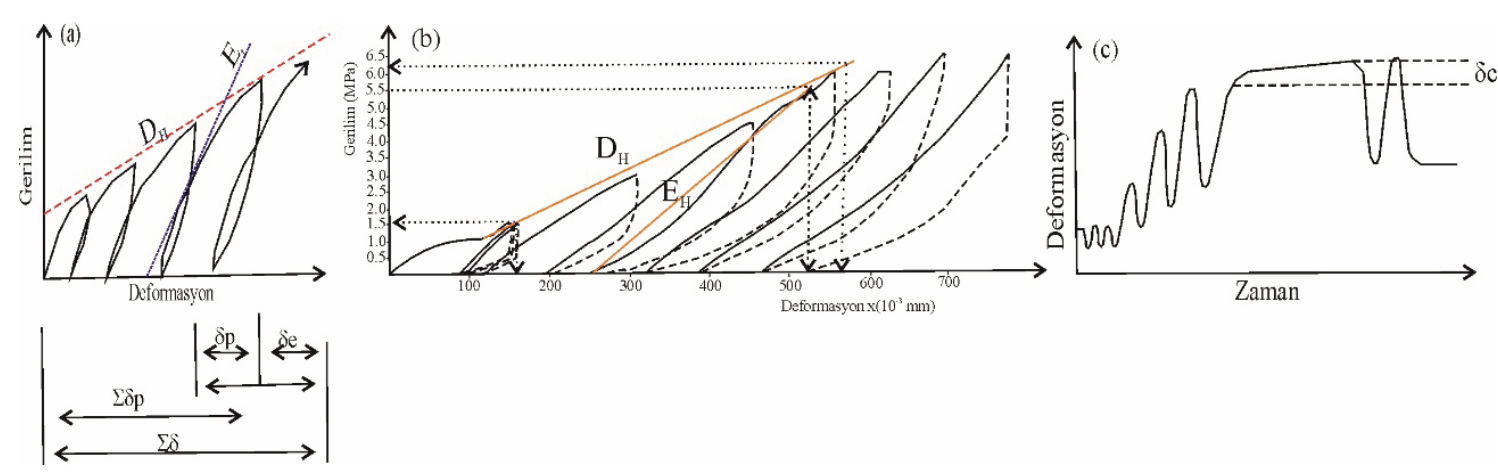

Şekil 13. Plaka yükleme deneyi a) gerilim-deformasyon grafiği b) örnek deneyde deformasyon modülü ve elastisite modülünün belirlenmesi c) deney programına göre uygulanmış deformasyon-zaman grafiği (Narin vd., 1986).

Figure 13. Plate loading test a) stress-deformation graph b) determination of deformation modulus and elasticity modulus from a sample test c) deformation-time graph applied according to test programme (Narin et al., 1986). 
Kayabaşı

Şekil 13 b'de örnek bir plaka yükleme deneyinden elastisite modülü ile deformasyon modülü belirlenmesine yönelik teğet eğrilerle aşağıdaki işlemlerle elastisite modülü ve deformasyon modülü belirlenir.

$\mathrm{E}_{\mathrm{H}}=$ ла $\left(1-\gamma^{2}\right) / 2 .(\Delta \sigma / \Delta \delta \mathrm{et})=\left(3.14 \times 17.75 \mathrm{x}\left(1-0.25^{2}\right)\right.$

$/ 2) \times(5.5 /(536-246))=4.85 \mathrm{GPa}$

$\mathrm{D}_{\mathrm{H}}=$ ла $\left(1-\gamma^{2}\right) / 2 .(\Delta \sigma / \Delta \delta \mathrm{d})=\left(3.14 \times 17.75 \mathrm{x}\left(1-0.25^{2}\right)\right.$

$/ 2) \mathrm{x}(4.5 /(561-162))=2.88 \mathrm{GPa}$

Yukarıdaki eşitliklerde

$\mathrm{a}=$ Yükleme plakası yarı çapı $(17.75 \mathrm{~cm})$

$\gamma=$ Poisson oran1 $(\mathrm{Bu}$ oran laboratuvar deneyleri ile bulunabileceği gibi kabule dayalı da olabilir : $(\gamma=0.25)$

$\Delta \sigma=$ Basınç artış farkı (MPa)

$\Delta \delta_{\text {et }}, \Delta \delta_{\mathrm{d}}=$ Basınç artış farkına bağlı deformasyon artış farkları (mm)

Oyo 200 Dilatometresi (Elastmeter 200) deneyi, baraj, tünel, köprü ayağı gibi yapıların temelini oluşturan kaya kütlesinin elastik modüllerinin (E, D), akma dayanımının $\left(\mathrm{P}_{\mathrm{y}}\right)$, kırılma dayanımının $\left(\mathrm{P}_{\max }\right)$, zemin sabitinin (k) ve deformasyon özelliklerini belirlemede kullanılır. Oyo 200 Dilatometre deneyi Elektrik İşleri Etüt İdaresinin hazırladığı deney normuna göre yapılmıştır (EİE-124, 1992; ASTM 477, 1970). Deney kuyu içinde sondanın basınç yüklenmesiyle yapılır (Şekil 14). Yükleme hızı uygulamada $0.1-1 \quad \mathrm{MPa} / \mathrm{cm} /$ dakika arasında değerler olarak alınmakdadır. Genel bir kural olarak zayıf kayalar daha yavaş, sağlam kayalar daha hızlı yüklenebilir. Şekil 14'de görüleceği gibi üç kez 3.4 MPa yükleme yapılmış, üçüncü yükleme sonunda iki saat bekleme yapıldıktan sonra yük boşaltılmış sonra $6.4 \mathrm{MPa}, 9.4 \mathrm{MPa}$ ve $12.4 \mathrm{MPa}$ yükleme ve boşaltma yapılarak deneye son verilmiştir. Deneyin her yükleme için 2 dakika süre sonrasında yüklemede 5 dakika beklenerek deformasyon kayıtları alınmıştır.

\section{Deriner Baraj Yeri Modül Değerlendirmeleri}

Galeri içi plaka yükleme deneyleri ve galeri içlerinde yapılan dilatometre deneyleri sonuçları değerlendirilmiştir. $\mathrm{Bu}$ yükleme deneylerinden belirlenen deformasyon modülleri ile elastisite modülleri arasında yapılan regresyon analizinde üs fonksiyon ile en yüksek determinasyon katsayıs1 $\left(\mathrm{R}^{2}\right)=0.88$ belirlenmiştir (Şekil 15). Örnekleyecek olursak Elastisite modülü $(E)=0.5$ MPa olması durumunda, deformasyon modülü (D) $=0.3 \mathrm{MPa}$ olacaktır. E ve D modül değerlerinin küçük değerlerde birbirlerine oransal olarak yakın olduğu fakat her iki değerin yükselmesi durumunda saçılmaların arttığı gözlenmektedir. Kaya kütledeki süreksizliklerin kapanması ve kaya kütlenin dayanımının litolojik dayanıma bağlı kaldığı durumda tek bir döngüdeki düşük deformasyon aralığı E modül değerini yüksek belirlerken, birkaç döngü eğiminden belirlenen D modül değerinin daha düşük olmasına neden olacaktır. $\mathrm{Bu}$ farklılık, yüksek gerilimlerde belirlenen E modül ve $\mathrm{D}$ modül değerlerinde daha fazla belirgindir. 

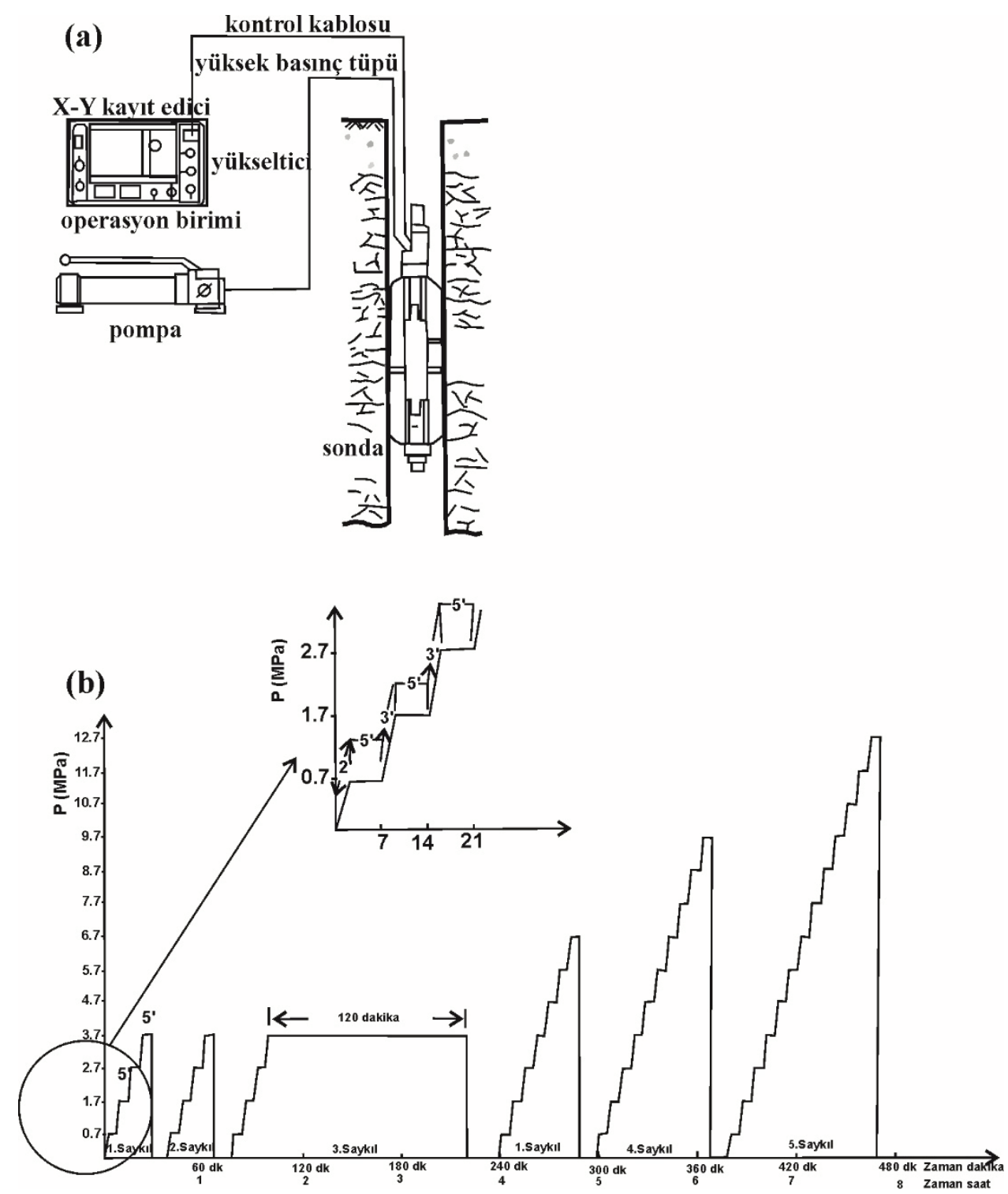

Şekil 14. a) Dilatometre deneyi cihazları şematik görünümü, b) Deriner baraj yeri dilatometre deneyi yükleme program1.

Figure 14. a) Schematic view of dilatometer test equipment, b) loading programme of dilatometer test applied at Deriner dam site. 
Kayabaşı

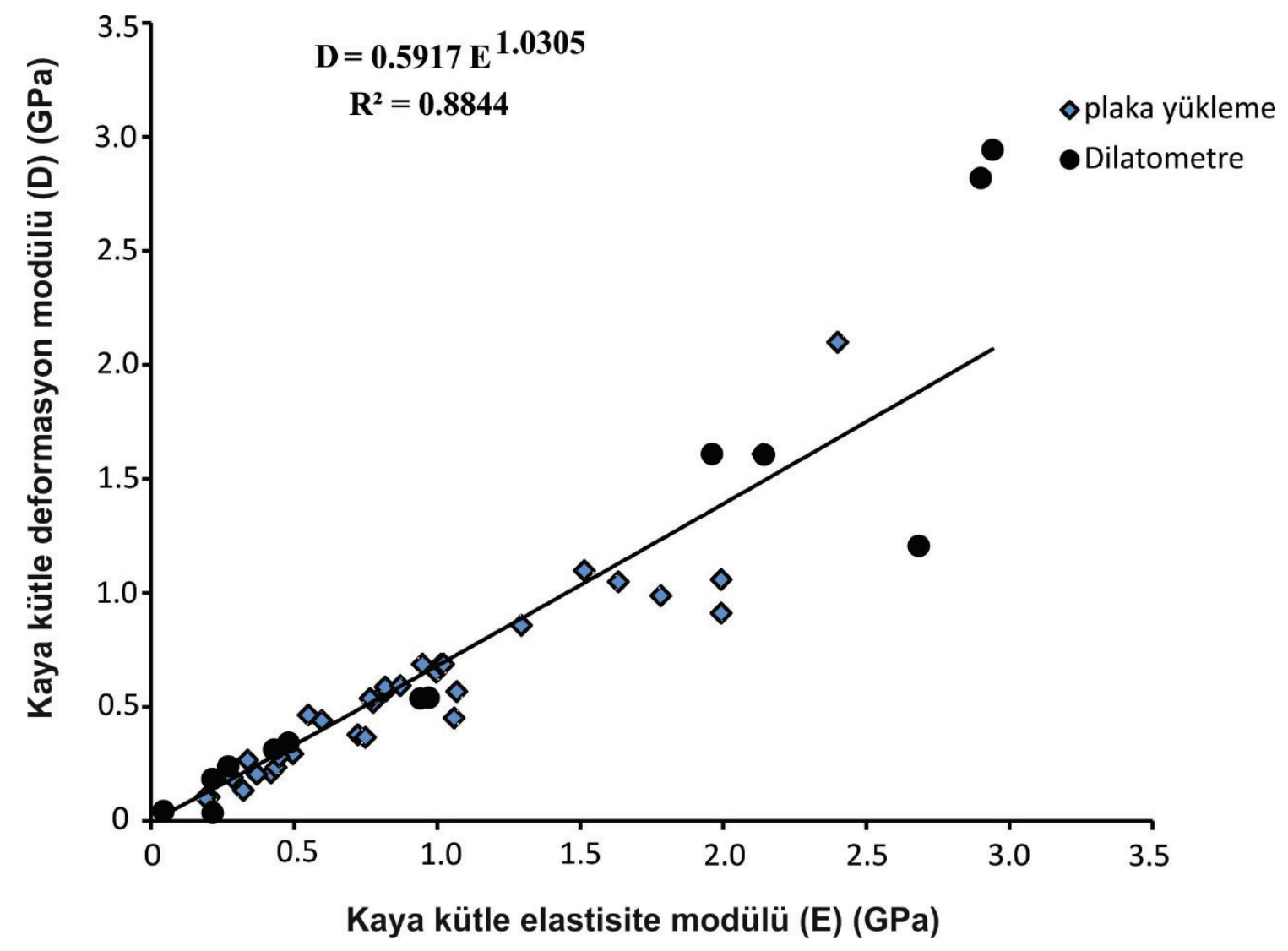

Şekil 15. Kaya kütle elastisite modülü (E) ve Kaya kütle deformasyon modülü (D) arasındaki eşitliği gösteren grafik. Figure 15. Graph showing the relation between rock mass elasticity modulus (E) and rock mass deformation modulus (D).

Deney lokasyonları birbirine çok yakın 6 adet plaka yükleme deneyi ve dilatometre deneyi belirlenmiş ve bu deneylerden hesaplanan modüller arasında regresyon analizi yapılmıştır (Şekil 16). Bu analizde kullanılan veri sayısının az olmasının nedeni plaka yükleme ve dilatometre deneylerinin yapıldığı lokasyonların çok yakın olmasının şartının aranmasıdır. Deney lokasyonları arasının mesafe olarak fazla olması, deneyin yapıldığı yön farklılığ1, kaya kütlenin anizotropisi gibi faktörler sonucu etkileyecektir. Şekil 16a' da plaka yükleme deneyi deformasyon modülleri ile dilatometre deneylerinden belirlenen deformasyon modülleri arasında yapılan regresyon analizinde üstel fonksiyon ile en yüksek determinasyon katsayısı $\left(\mathrm{R}^{2}\right)=0.98$ belirlenmiştir. Determinasyon katsayısının yüksek olması, her iki deneyde de belirlenen modül değerlerinin birbirinden çok farklılıklar göstermediği görülmektedir. Şekil 16a'da görüleceği gibi 5 adet veri karşılaştırılmıştır. Çizelge 1'de verilmiş olan SK 9E deneyinden belirlenen modül değerleri $\left(\mathrm{D}_{\mathrm{D}}=12.07 \mathrm{GPa}\right.$ ve $\left.\mathrm{D}_{\mathrm{H}}=1,91 \mathrm{GPa}\right)$ uyumluluk göstermediği için regresyon analizine alınmamıştır. Şekil 16b'de ise plaka yükleme deneyi elastisite modülleri ile dilatometre deneylerinden belirlenen elastisite modülleri arasında yapılan regresyon analizinde 
üs fonksiyonu ile en yüksek determinasyon katsay1S1 $\left(\mathrm{R}^{2}\right)=0.71$ belirlenmiştir. Şekil 16b'de görüleceği gibi 4 adet veri karşılaştırılmıştır. Çizelge 1'de verilmiş olan SK 9E deneyinden belirlenen modül değerleri $\left(\mathrm{E}_{\mathrm{D}}=26.83 \mathrm{GPa}\right.$ ve $\left.\mathrm{E}_{\mathrm{H}}=5.83 \mathrm{GPa}\right)$ ile SK-12 deneyinden belirlenen modül değerleri $\left(\mathrm{E}_{\mathrm{D}}=4.80 \mathrm{GPa}\right.$ ve $\mathrm{E}_{\mathrm{H}}=0.82$ $\mathrm{GPa})$ değerleri uyumluluk göstermediği için regresyon analizine alınmamıştır. SK 9E ve SK12 kuyularının olduğu galeri bölümünün açımı sırasında patlatmadan daha çok hasar aldığı ve elastisite modüllerinin daha çok saçılım yapması, verilerin daha net farklılık göstermesinden elastisite modülünün, deformasyon modülüne göre daha hassas olduğunu söyleyebiliriz. Bunun nedeni ise elastisite modülünün tek bir döngüden belirlenirken, deformasyon modülünün birkaç döngüden belirlenmesidir.

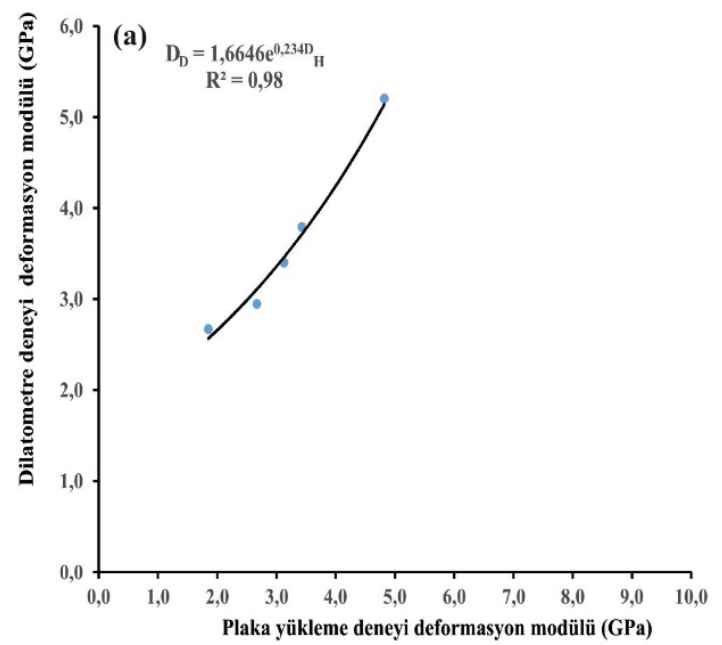

Deriner Baraj yerinden alınan örneklerden laboratuvarda belirlenen $\mathrm{E}_{\mathrm{LD}}$ ve $\mathrm{E}_{\mathrm{LS}}$ modüllerinin regresyon analizi sonucu Şekil 17a'da verilmiştir. Logaritmik fonksiyon ile en yüksek determinasyon katsayısı $\left(\mathrm{R}^{2}\right)=0.52$ belirlenmiştir. Regresyon analizi eşitliğinden de görüleceği gibi $\mathrm{E}_{\mathrm{LD}}$ değerleri devamlı olarak $\mathrm{E}_{\mathrm{LS}}$ değerlerinden fazla çıkmaktadır. $E_{L S}$ değerinin 20 olması durumunda $\mathrm{E}_{\mathrm{LD}}$ değeri 36 olmaktadır. $\mathrm{K}$ değeri $\left(\mathrm{E}_{\mathrm{LD}} / \mathrm{E}_{\mathrm{LS}}\right)=1.8$ olur. $\mathrm{E}_{\mathrm{LS}}$ değerinin 50 olmas durumunda $\mathrm{E}_{\mathrm{LD}}$ değeri 56.87 olmaktadır. K değeri $\left(\mathrm{E}_{\mathrm{LD}} / \mathrm{E}_{\mathrm{LS}}\right)=1.14$ olur. $\mathrm{E}_{\mathrm{LD}}$ ve $\mathrm{E}_{\mathrm{LS}}$ değerlerinin artışıyla $\mathrm{K}$ değerinin 1'e yaklaşmasını kayaç malzemede bozunma derecesinin azalmasından kaynaklanmakta olduğunu söyleyebiliriz.

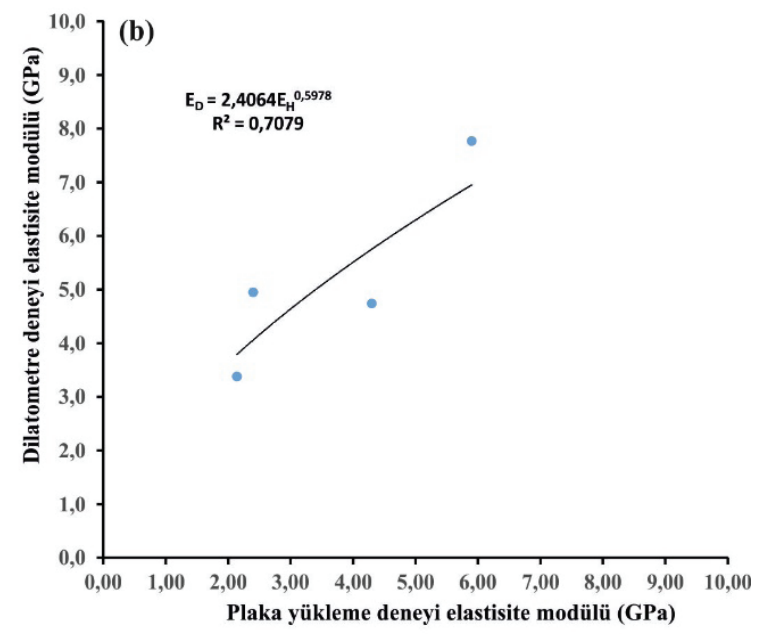

Şekil 16. a) Plaka yükleme deneyi deformasyon modülü ile dilatometre deneyi deformasyon modülünün karşılaştırılması b) Plaka yükleme deneyi elastisite modülü ile dilatometre deneyi elastisite modülünün karşılaştırılması.

Figure 16. a) Correlation of plate loading test deformation modulus and dilatometere test deformation modulus b) Correlation of plate loading test elasticity modulus and dilatometere test elasticity modulus. 
Kayabaşı

Çizelge 1. Deriner baraj yerinde farklı deneylerle belirlenen modüller.

Table 1. Modules determined by means of different tests at Deriner dam site.

\begin{tabular}{|c|c|c|c|c|c|c|c|c|c|}
\hline \multirow[t]{2}{*}{$\begin{array}{l}\text { Kuyu } \\
\text { no }\end{array}$} & \multirow{2}{*}{$\begin{array}{l}\text { Galeri } \\
\text { LA-1 }\end{array}$} & \multirow[t]{2}{*}{$\begin{array}{l}\text { Deney zonu } \\
\text { (m arası) }\end{array}$} & \multirow[t]{2}{*}{ Litoloji } & \multicolumn{4}{|c|}{$\begin{array}{l}\text { Elastisite } \\
\text { modülü } \\
(\mathrm{GPa})\end{array}$} & \multicolumn{2}{|c|}{$\begin{array}{l}\text { Deformasyon } \\
\text { modülü } \\
(\mathrm{GPa})\end{array}$} \\
\hline & & & & $\mathrm{E}_{\mathrm{D}}$ & $\mathrm{E}_{\mathrm{H}}$ & $\mathrm{E}_{\mathrm{LS}}$ & $\mathrm{E}_{\mathrm{LD}}$ & $\mathrm{D}_{\mathrm{D}}$ & $\mathrm{D}_{\mathrm{H}}$ \\
\hline SK-1 & $7.30 \mathrm{~m}$ düşey & $2-3$ & Kuvars diyorit & 2.40 & 4.95 & & & 2.67 & 2.96 \\
\hline SK-2 & 24.20 düşey & $2-3$ & Diyabaz & 5.90 & 7.77 & 47.19 & 52.54 & 48.20 & 52.02 \\
\hline SK-2E & 24.20 m sağ-yatay & $7-8$ & Kuvars diyorit & 19.60 & & 40.00 & 59.27 & 16.10 & \\
\hline SK-3E & $\begin{array}{l}45.00 \mathrm{~m} \\
\text { Sağ yatay }\end{array}$ & $7-8$ & Diyabaz & 9.42 & & 33.83 & 42.52 & 53.80 & \\
\hline \multirow[t]{2}{*}{ SK-6 } & 21.50 m düşey & $2-3$ & $\begin{array}{l}\text { Kuvarsl1 } \\
\text { diyorit }\end{array}$ & 53.60 & & 20.00 & 25.16 & 9.65 & \\
\hline & LA-4 & & & & & & & & \\
\hline SK-7 & $\begin{array}{l}46.00 \mathrm{~m} \\
\text { düşey }\end{array}$ & $7-8$ & Fay zonu & 4.30 & & 47.78 & 44.00 & & \\
\hline SK-7A & $\begin{array}{l}45.50 \mathrm{~m} \\
\text { So-yatay }\end{array}$ & $7-8$ & Fay Zonu & 2.15 & & 61.39 & 49.16 & 0.36 & \\
\hline \multirow[t]{2}{*}{ SK-9 } & $\begin{array}{l}21.70 \mathrm{~m} \\
\text { düşey }\end{array}$ & $2-3$ & Kuvars diyorit & 2.14 & 3.38 & & & 1.85 & 2.67 \\
\hline & RA-3 & & & & & & & & \\
\hline \multirow[t]{2}{*}{ SK-9E } & $\begin{array}{l}24.20 \\
\text { Sol-yatay }\end{array}$ & $2-3$ & Kuvars diyorit & 26.83 & 5.93 & 20.00 & 42.22 & 12.07 & 1.91 \\
\hline & RA-5 & & & & & & & & \\
\hline SK-11E & 45.00 sağ-yatay & $7-8$ & Kuvars diyorit & 21.43 & & 3.00 & 49.82 & 16.07 & \\
\hline SK-12 & 51.70 düşey & $2-3$ & Kuvars diyorit & 4.80 & 0.82 & & 3.60 & 3.43 & 3.79 \\
\hline SK-12 & 51.70 düşey & $7-8$ & Kuvars diyorit & 29.41 & & 3.29 & 56.87 & 29.44 & \\
\hline SK-12E & 54.30 sağ-yatay & $2-3$ & Kuvars diyorit & 4.30 & 4.74 & & & 3.13 & 3.40 \\
\hline
\end{tabular}

Şekil 17b'de ise Deriner Baraj yerinde yapilan dilatometre deneylerinden belirlenen kaya kütle dilatometre deformasyon modülü $\left(\mathrm{D}_{\mathrm{D}}\right)$ ile kaya kütle dilatometre elastisite modülü $\left(E_{D}\right)$ değerleri arasında yapılan regresyon analizi sonucu verilmiştir. Üs fonksiyon ile en yüksek determinasyon katsayısı $\left(\mathrm{R}^{2}\right)=0.84$ belirlenmiştir. Kaya kütle dilatometre deformasyon modülü $\left(\mathrm{D}_{\mathrm{D}}\right)$ kaya kütle dilatometre elastisite modülü $\left(E_{D}\right)$ arasındaki farkın düşük değerlerde kapandığı, yüksek değerlerde ise farkın açıldığ görülmektedir. 

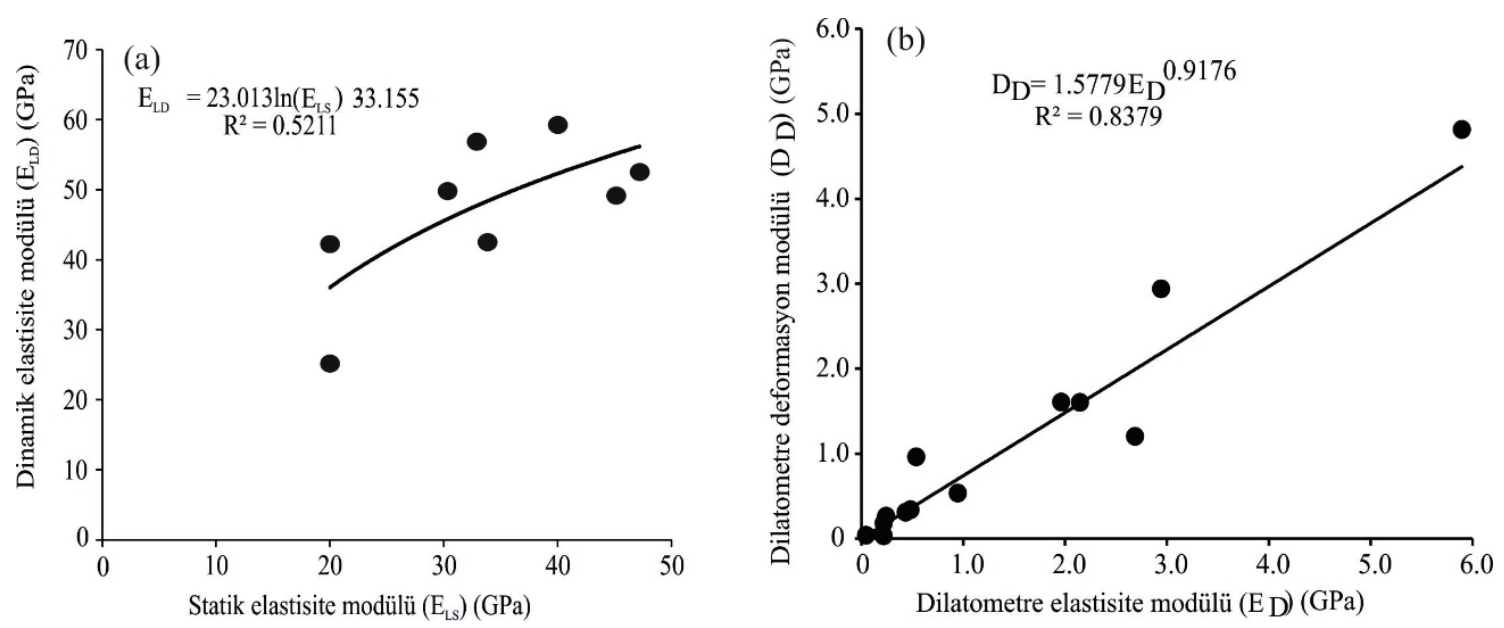

Şekil 17. a) Kaya malzemesi statik elastisite modülü ile kaya malzemesi dinamik elastisite modülü arasında yapılan regresyon analizi grafiği b) dilatometre elastisite modülü ile deformasyon modülü arasında yapılan regresyon analizi grafiği.

Figure 17. a) regression analysis graph between static elasticity and dynamic elasticity modulusses b) regression analysis graph between dilatometer elasticity moduluses and dilatometer deformation modulusses.

\section{Ermenek (Karaman) Barajı Dilatometre Deneyi Çalışmaları}

Ermenek Barajı için Erikli deresi civarında yapılmas1 projelendirilen yeralt1 santrali temel sahasinda SK-126 (50 m), SK-127 (80 m) ve SK-131 (70 m) kuyuları açılmıştır. (Kaya ve Kayabaşı, 1998). Bu kuyulardan üçünde toplam 20 adet dilatometre deneyi yapılmıştır (Şekil 18).

Dilatometre deneyleri üç kez $3.4 \mathrm{MPa}$, üç kez 6.4 MPa ve üç kez 9.4 MPa yükleme boşaltma döngüleri halinde yapılmıştır. Her yükleme 2 dakikalık yükleme ve 3 dakikalık bekleme süreciyle yapılmıştır (Şekil 19).

Dilatometre eğrileri üzerinde eğim ölçümleri yapılarak deformasyon modülü ve elastisite modülü Eşitlik 6 ile belirlenir.

$$
E_{D} \text { veya } D_{D}=(1+\mu) r_{m} \frac{\Delta P}{\Delta r}
$$

Burada

$\mathrm{r}=$ kuyu çapı

$\mathrm{r}_{\mathrm{m}}=$ kuyu yarıçap $1+\Delta \mathrm{r} / 2$

$\mu=$ Poisson oran 1

Şekil 20'de SK-126 nolu kuyunun 18.3019.30 metrelerinde yapılan dilatometre deneyi grafiği ve teğet modül çizgileri görülmektedir. Çizelge 2'de ise deney verilerinin değerlendirilmiş sonuçları verilmektedir. Deformasyon modülü değerleri, elastisite modüllerinden fazla çıkmaktadır ve hesaplandığ yükleme ve boşaltma eğrilerine göre değerleri değişmektedir. 
Kayabaşı

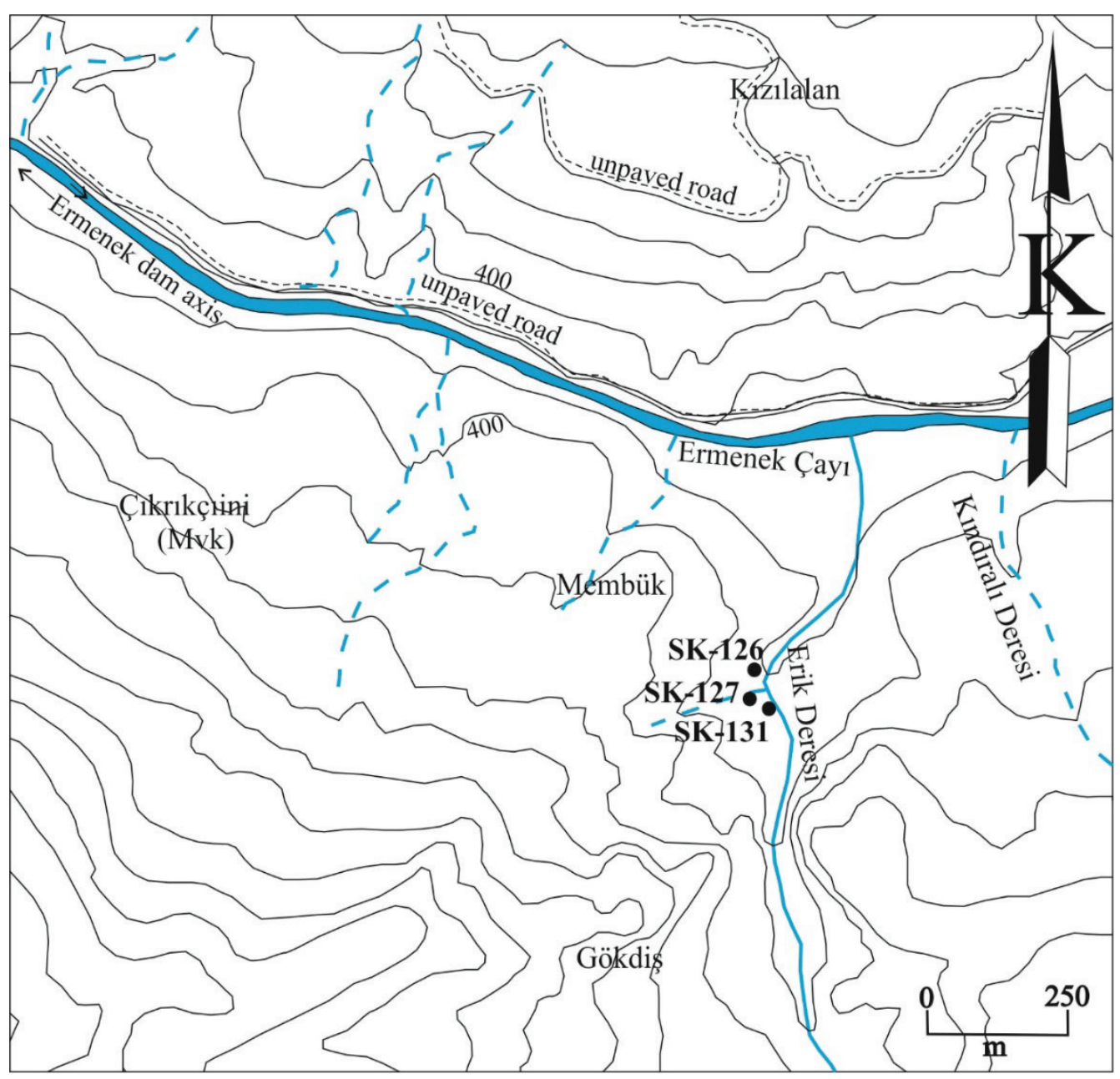

Şekil 18. Ermenek (Karaman) Baraj1 santral yeri sondaj kuyusu lokasyon haritası.

Figure 18. Powerhouse borehole location map of Ermenek dam (Karaman). 


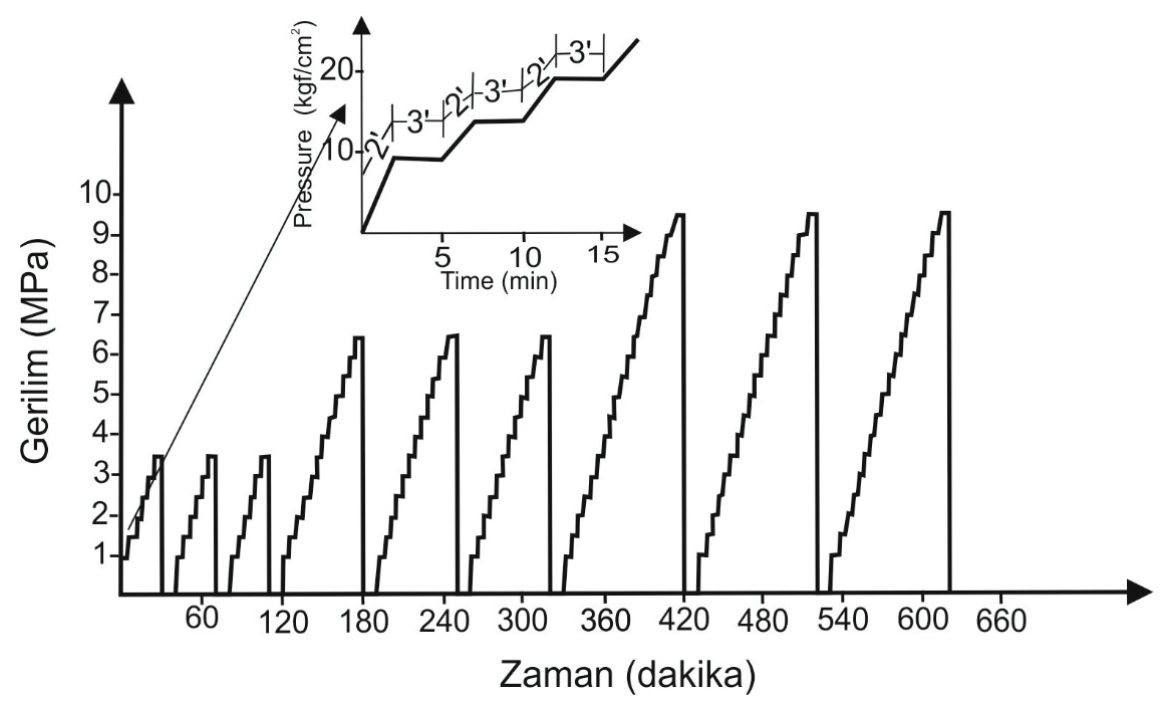

Şekil 19. Ermenek (Karaman) Baraj1 santral yeri dilatometre deneyi programı.

Figure 19. Ermenek dam site dilatometer test programme.

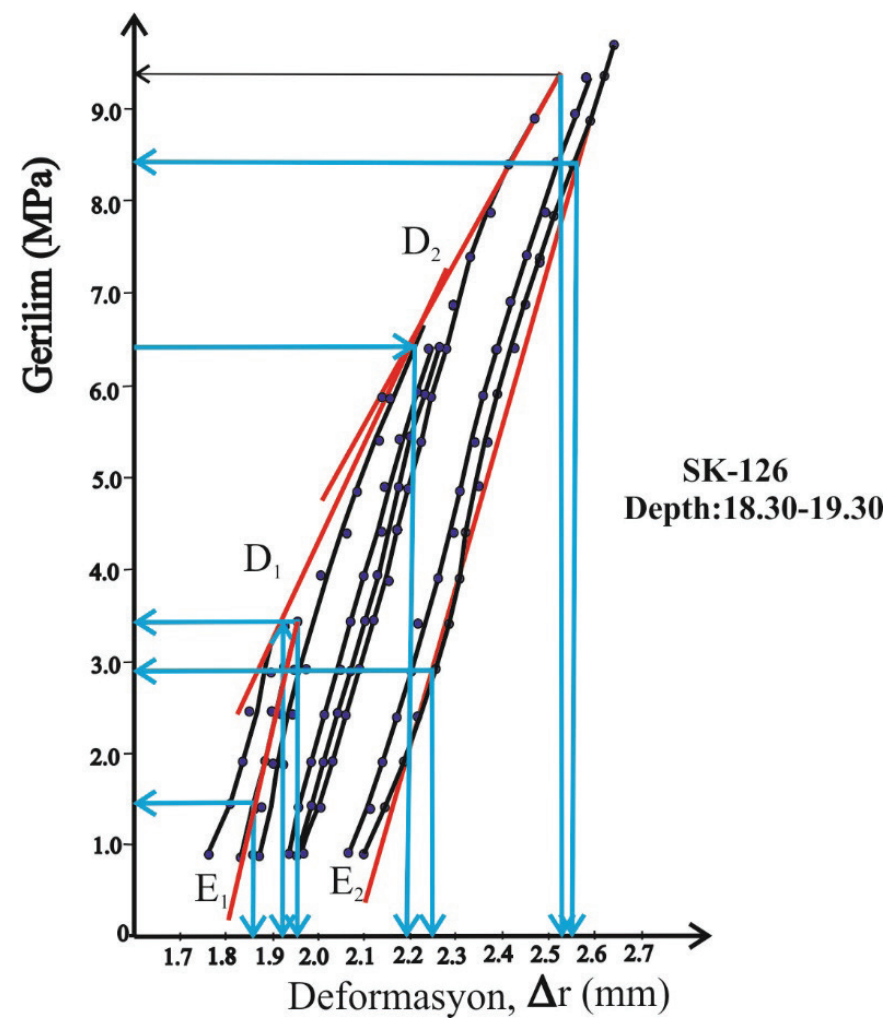

Şekil 20. SK-126 kuyusunda yapılan dilatometre deneyi grafiği.

Figure 20. Dilatometer test graph performed in borehole SK-126. 
Kayabaşı

Çizelge 2. Ermenek Barajı santral yeri dilatometre deneyi örnek deney verisi.

Table 2. Dilatometer test sample data from Ermenek dam powerhouse site.

\begin{tabular}{cccccccccc}
\hline Kuyu no & Derinlik & $\begin{array}{c}\mathrm{P}_{1} \\
(\mathrm{MPa})\end{array}$ & $\mathrm{P}_{2}(\mathrm{MPa})$ & $\mathrm{r}_{1}$ & $\mathrm{r}_{2}$ & $\begin{array}{c}\Delta \mathrm{p} \\
(\mathrm{cm})\end{array}$ & $\begin{array}{c}\Delta \mathrm{r} \\
(\mathrm{cm})\end{array}$ & $\begin{array}{c}\mathrm{rm} \\
(\mathrm{cm})\end{array}$ & $\begin{array}{c}\text { Modül } \\
(\mathrm{MPa})\end{array}$ \\
\hline SK-126 & $18.30-$ & 1.4 & 3.4 & 0.187 & 0.198 & 20 & 0.011 & 3.80 & $\mathrm{E}_{1}=8.981$ \\
& 19.30 & 2.9 & 8.4 & 0.225 & 0.255 & 55 & 0.035 & 3.80 & $\mathrm{E}_{2}=9.056$ \\
& & 3.4 & 6.4 & 0.192 & 0.219 & 30 & 0.027 & 3.80 & $\mathrm{D}_{1}=5.489$ \\
& & 6.4 & 9.4 & 0.219 & 0.253 & 30 & 0.034 & 3.80 & $\mathrm{D}_{2}=4.358$ \\
\hline
\end{tabular}

Ermenek Baraj1 santral yeri dilatometre deneylerinden belirlenen deformasyon modülleri ile elastisite modülleri arasında yapılan regresyon analizinde üs fonksiyon ile en yüksek determinasyon katsayısı $\left(\mathrm{R}^{2}\right)=0.79$ belirlenmiştir (Şekil 21). Örnekleyecek olursak $E_{D}=0.5 \mathrm{~kg} / \mathrm{cm}^{2}$ olmasi durumunda $\mathrm{D}_{\mathrm{D}}=0.310 \mathrm{MPa}$ olacaktır. $\mathrm{D}_{\mathrm{D}}$ ve $\mathrm{E}_{\mathrm{D}}$ değerlerinin küçük değerlerde birbirlerine oransal olarak yakın olduğu fakat her iki değerin yükselmesi durumunda saçılmaların daha fazlalaştığı görülmüştür.
Çizelge 3'te kaya malzemesinde ve kaya kütlesinde yapilan deneylerden belirlenen modüller arasında gerçekleştirilen regresyon analizleri sonuçları ve belirlenen görgül eşitlikler verilmiştir. En yüksek determinasyon katsayısı $\left(\mathrm{R}^{2}=0.98\right)$ Deriner Baraj1 eksen yerinde galeri içlerinde yapılan dilatometre deneyinden belirlenen deformasyon modülü ile plaka yükleme deneylerinden bulunan deformasyon modüllerinin karşılaştırılması sonucunda üstel fonksiyonla belirlenmiştir.

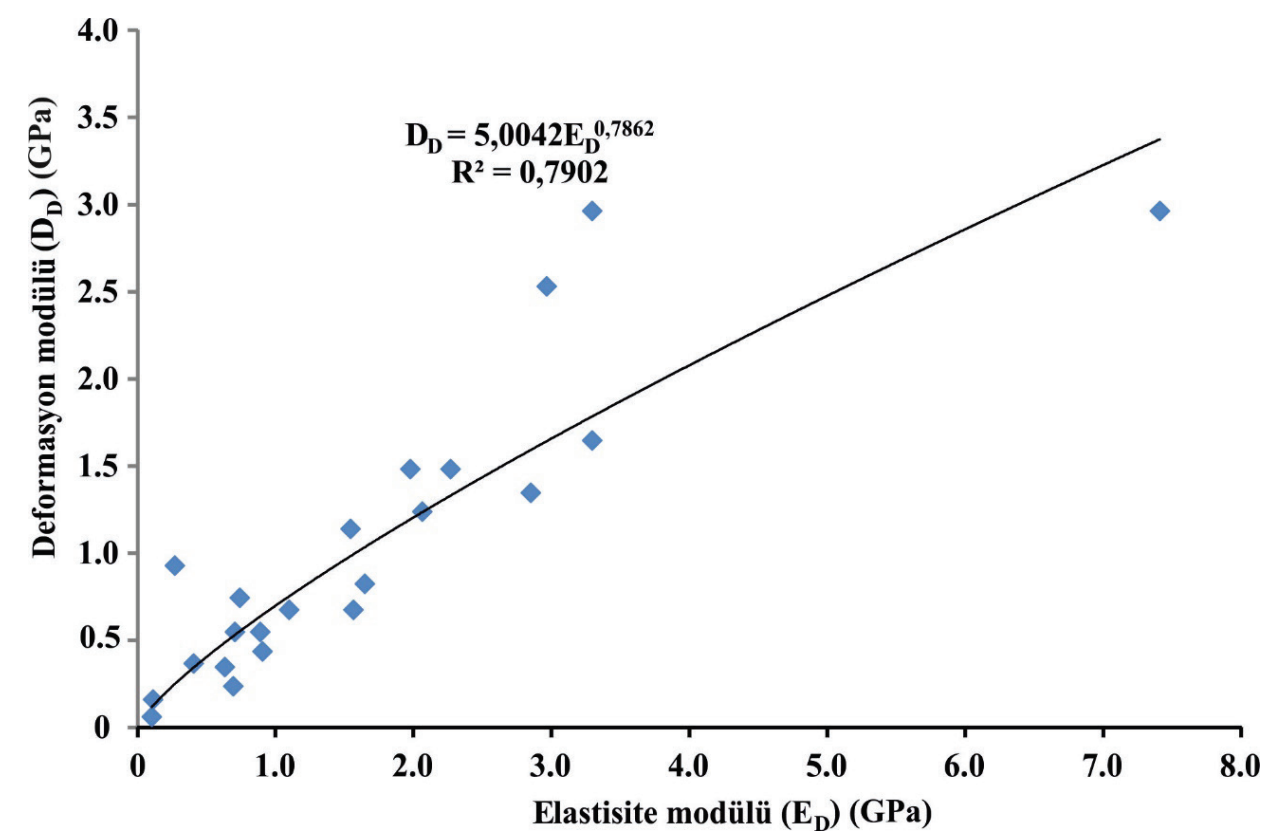

Şekil 21. Dilatometre deneyinden belirlenen $\mathrm{D}_{\mathrm{D}}$ ile $\mathrm{E}_{\mathrm{D}}$ değerleri arasında yapılan regresyon analizi grafiği. Figure 21. The regression analysis graph of $D_{D}$ and $E_{D}$ determined by dilatometer tests. 
Çizelge 3. Bu çalışmada belirlenen görgül eşitlikler.

Table 3. Empirical equations determined in this study.

\begin{tabular}{|c|c|c|c|c|}
\hline Parametre & lokasyon & Deney adı & Görgül eşitlik & $\begin{array}{l}\text { Determinasyon } \\
\text { katsay1S1 }\left(\mathrm{R}^{2}\right)\end{array}$ \\
\hline$D_{H}, E_{H}$ & Deriner Baraj1 & $\begin{array}{l}\text { Plaka yükleme deneyi, } \\
\text { Dilatometre deneyi }\end{array}$ & $\mathrm{D}_{\mathrm{H}}=0.5917\left(\mathrm{E}_{\mathrm{H}}\right)^{1,0305}$ & 0.88 \\
\hline $\mathrm{D}_{\mathrm{D}}, \mathrm{D}_{\mathrm{H}}$ & Deriner Baraj1 & Dilatometre deneyi & $\mathrm{D}_{\mathrm{D}}=1.6646 \mathrm{e}_{\mathrm{H}}^{0.2340\left(\mathrm{D}_{)}\right)}$ & 0.98 \\
\hline$E_{H}, E_{D}$ & Deriner Baraj1 & $\begin{array}{l}\text { Dilatometre ve plaka } \\
\text { Yükleme deneyi }\end{array}$ & $\mathrm{E}_{\mathrm{H}}=2.4064 \mathrm{D}_{\mathrm{H}}^{0.5978}$ & 0.71 \\
\hline $\mathrm{E}_{\mathrm{LD}}, \mathrm{E}_{\mathrm{LS}}$ & Deriner Baraj1 & $\begin{array}{l}\text { Statik elastisite modülü ve } \\
\text { dinamik elastisite modülü tayini }\end{array}$ & $\mathrm{E}_{\mathrm{LD}}=23.013 \ln \left(\mathrm{E}_{\mathrm{LS}}\right)-33.155$ & 0.52 \\
\hline$D_{D}, E_{D}$ & Deriner Baraj1 & Dilatometre deneyi & $\mathrm{D}_{\mathrm{D}}=1.5779\left(\mathrm{E}_{\mathrm{D}}\right) 0.9176$ & 0.84 \\
\hline$D_{D}, E_{D}$ & $\begin{array}{l}\text { Ermenek } \\
\text { Baraj1 }\end{array}$ & Dilatometre deneyi & $\mathrm{D}_{\mathrm{D}}=5.0042\left(\mathrm{E}_{\mathrm{D}}\right) 0.7862$ & 0.79 \\
\hline
\end{tabular}

\section{SONUÇLAR VE ÖNERILER}

$\mathrm{Bu}$ çalışmada Deriner Baraj1/Artvin ve Ermenek Baraj1/Karaman'da yapılan yerinde deneylerden belirlenen kaya kütle modülleri ve laboratuvar deneylerinden belirlenen dinamik ve statik modül değerleri tanımlanmıştır. Deney yöntemlerine göre modüller birbirlerinden farkl1lıklar göstermektedir. Bununla birlikte, projeler hazırlanırken modüller yanlış olarak birbirinin yerine kullanılabilmektedir. Kaya kütle deformasyon modülü ve kaya kütle elastisite modülü yerinde deneylerle belirlenirken, kaya malzemesi statik elastisite modülü ve kaya malzemesi dinamik elastisite modülü ise laboratuvar deneyleriyle belirlenir. Laboratuvarda belirlenen kaya malzemesi statik elastisite modülü kaya malzemesi dayanımının karşılaştırılmasıyla, kaya malzemesinin sinıflandırılması yapılmaktadır (Deere ve Miller, 1966). Kaya malzemesinin kaya kütleyici tam olarak tanımlayıcı olmaması, yerinde deneylerin yapılmasına yol açmıştır. Deformasyon modülü terimi yük deformasyon eğrisinin elastik ve kalıcı deformasyon her iki kısmı da kapsar iken elastisite modülü terimi elastik sınırları kapsar (Goodman, 1989). Kaya kütle deformasyon modülü değerleri projelendirmelerde yap1 ile temel etkileşimlerinin belirlenmesinde girdi parametresi olarak kullanılmaktadır.

$\mathrm{Bu}$ çalışmada anlatım karmaşası olmaması için belirlendiği deneyin adı modül adı önüne yazılarak simgelendirme yapılarak, kaya kütle dilatometre deneyi elastisite modülü $\left(\mathrm{E}_{\mathrm{D}}\right)$, kaya kütle plaka yükleme deneyi elastisite modülü $\left(\mathrm{E}_{\mathrm{H}}\right)$, kaya malzemesi statik elastisite modülü $\left(\mathrm{E}_{\mathrm{LS}}\right)$, kaya malzemesi dinamik elastisite modülü $\left(\mathrm{E}_{\mathrm{LD}}\right)$, kaya kütle dilatometre deformasyon modülü $\left(\mathrm{D}_{\mathrm{D}}\right)$, kaya kütle plaka yükleme deneyi deformasyon modülü $\left(D_{H}\right)$ şeklinde ifade edilmiştir. Modüller arasında regresyon analizleri yapılarak korelasyon katsayıları ve aralarındaki fonksiyonel ilişkiler belirlenmeye çalışılmıştır.

Çalışmanın ilk aşamasında Deriner barajında açılan galerilerde yapılan dilatometre ve plaka yükleme deneylerinden birbirine yakın olan deneylerden $E_{D}, E_{H}, D_{D}, D_{H}$ değerleri ile bu deneylerin lokasyonlarında alınan kaya malzemelerinden laboratuvarda belirlenen $E_{L S}$ ve 
Kayabaşı

$E_{L D}$ değerleri ile Ermenek Baraj1/Karamanda yer altı santrali temel etüdü için yapılan dilatometre deneylerinden belirlenen $D_{D}$ ve $E_{D}$ değerleri derlenmiştir.

Çalışmanın ikinci aşamasında tüm kaya modülleri arasında basit regresyon analizleri yapılmıştır. Deriner Baraj'ında yapılan plaka yükleme ve dilatometre deneylerinden belirlenen deformasyon modülü ve elastisite modülü değerleri arasında üs fonksiyon ile $\mathrm{R}^{2}=0.88$ determinasyon katsayısı belirlenmiştir. Elastisite modülü ve Deformasyon modülü değerlerinin küçük değerlerde birbirlerine oransal olarak yakın olduğu fakat her iki değerin yükselmesi durumunda saçılmaların arttığ Kujundzíc ve Grujíc (1966)'da $\mathrm{E}_{\mathrm{H}}$ ve $\mathrm{D}_{\mathrm{H}}$ değerlerinin farklılığının küçük değerlerde daha fazla olduğunu ifadesi bu çalışmada gerçekleşmemiştir. Galera vd. (2005) in önerdiği $\mathrm{E}_{\mathrm{H}} / \mathrm{D}_{\mathrm{H}} \approx 7$ değerine bu çalışmada ulaş1lamamıştır. $\mathrm{Bu}$ çalışmada $\mathrm{E} / \mathrm{D}=1.46$ değeri bulunmuştur.

Deriner baraj1 araştırma galerilerinde aynı yüzeyde yapılan 6 adet deneyin $D_{D}$ ve $E_{H}$ deney verileriyle yapilan regresyon analizinde üstel fonksiyon ile en yüksek determinasyon katsayısı $\left(\mathrm{R}^{2}\right)=0.98$ belirlenmiştir. SK 9E deneyinden belirlenen modül değerleri $\left(\mathrm{D}_{\mathrm{D}}=12.07 \mathrm{GPa}\right.$ ve $\left.\mathrm{D}_{\mathrm{H}}=1,91 \mathrm{GPa}\right)$ uyumluluk göstermediği için regresyon analizine alınmamıştır. Aynı şekilde $\mathrm{E}_{\mathrm{D}}-\mathrm{E}_{\mathrm{H}}$ değerleri arasında yapılan regresyon analizinde üssel fonksiyon ile en yüksek determinasyon katsayısı $\left(\mathrm{R}^{2}\right)=0.71$ belirlenmiştir. $\mathrm{Bu}$ analizde 4 adet veri karşılaştırılmıştır. SK 9E deneyinden belirlenen modül değerleri $\left(\mathrm{E}_{\mathrm{D}}=26.83\right.$ $\mathrm{GPa}$ ve $\left.\mathrm{E}_{\mathrm{H}}=5.83 \mathrm{GPa}\right)$ ile SK-12 deneyinden belirlenen modül değerleri $\left(\mathrm{E}_{\mathrm{D}}=4.80 \mathrm{GPa}\right.$ ve $\mathrm{E}_{\mathrm{H}}=0.82 \mathrm{GPa}$ ) değerleri uyumluluk göstermediğ $\mathrm{i}$ için regresyon analizine alınmamıştır. SK 9E ve SK-12 kuyuların açıldığg yüzeylerin galeri açımı sırasında patlatmadan etkilendiği belirlenmiştir.
Aynı yüzeylerde elastisite modüllerinin daha çok saçılım yapması, elastisite modülünün, deformasyon modülüne göre daha hassas olduğunu göstermektedir.

Deriner Baraj yerinden alınan örneklerden laboratuvarda belirlenen $\mathrm{E}_{\mathrm{LD}}$ ve $\mathrm{E}_{\mathrm{LS}}$ modüllerinin regresyon analizi sonucu logaritmik fonksiyon ile en yüksek determinasyon katsayıs1 $\left(\mathrm{R}^{2}\right)=0.52$ olarak belirlenmiştir. $\mathrm{K}\left(\mathrm{E}_{\mathrm{LD}} / \mathrm{E}_{\mathrm{LS}}\right)$ değerinin modül değerlerinin artışıyla birlikte 1 değerine yaklaşmasının nedenini bozunma derecesinin azalmasından kaynaklandığını söyleyebiliriz.

Deriner Baraj yerindeki galerilerde yapilan deneylerde belirlenen $D_{D}$ modül değerleri ile $\mathrm{E}_{\mathrm{D}}$ modülü değerleri arasında yapılan regresyon analizi sonucunda üs fonksiyon ile en yüksek determinasyon katsayısı $\left(\mathrm{R}^{2}\right)=0.84$ belirlenmiştir. $\mathrm{D}_{\mathrm{D}}$ değerleri ile $\mathrm{E}_{\mathrm{D}}$ değerleri arasındaki farkın düşük değerlerde kapandığı, yüksek değerlerde ise farkın açıldığı belirlenmiştir.

Ermenek Barajı santral yeri dilatometre deneylerinden belirlenen $D_{D}$ değerleri ile $E_{D}$ değerleri arasında yapılan regresyon analizinde üssel fonksiyon ile en yüksek determinasyon katsayısı $\left(R^{2}\right)=0.79$ belirlenmiştir. $D_{D}$ ve $E_{D}$ değerlerinin küçük değerlerde birbirlerine oransal olarak yakın olduğu fakat her iki değerin yükselmesi durumunda saçılmaların daha fazlalaştı̆̆

Kaya kütle dinamik elastisite modülü verisi olmadığı için bu çalışmalarda değerlendirmeye alınmamıştır.

Modül değerlerinin birbirinden farklı değerler olduğu, birbirlerinin yerine kullanılmasının proje için sakıncalar oluşturacağı bu çalışma ile ortaya konulmaya çalışılmıştır. Gerek veri azlığı ve gerekse her kaya kütle ortamının kendine ait farklı koşullar içinden bulunmasından dolayı bu çalışmada 
bulunan görgül eşitliklerin başka projelerde kullanılmamalı veya çapraz adımlı sınamalar yaparak kullanılmalıdır.

\section{KATKI BELIRTME}

$\mathrm{Bu}$ çalışmada, Elektrik İşleri Etüt İdaresi'nin projelendirdiği Aşağı Çoru Havzası HES Projelerinden birisi olan Deriner Barajı ile Ermenek baraj1 (Karaman) projelerinde yapılan yerinde deney verileri kullanılmıştır. 2012 yılında KHK ile kapatılan Güzide kurum Elektrik İşleri Etüt İdaresine, bu çalışmaların yapılmasını sağlamasından dolayı yazar minnetle teşekkür eder. Yazar, çalışmalarından faydalanılması nedeniyle mesai arkadaşları jeoloji mühendisleri Osman Narin'e, Osman Ceylan'a, Bayram Uysal'a, Ali Kaya'ya, Necmettin Gürsoy'a, Sadık Açan'a ve Nilgün Pehlivan'a ayrıca teşekkür eder.

\section{KAYNAKLAR}

Al-Shayea, NA., 2004. Effects of testing methods and conditions on the elastic properties of limestone rock. Engineering Geology, 74:139-156.

ASTM 477, 1970. Determination of in-situ Modulus of Deformation of rock.

ASTM D4394, 2017. Standard Test Method for Determining In Situ Modulus of Deformation of Rock Mass Using Rigid Plate Loading Method, ASTM International, West Conshohocken, www. astm.org.

ASTM D2845, 2008. Standard Test Method for Laboratory Determination of Pulse Velocities and Ultrasonic Elastic Constants of Rock (Withdrawn 2017), ASTM International, West Conshohocken, PA, www.astm.org.

Bieniawski, Z.T., 1978. Determining Rock Mass deformability. International Journal of Rock Mechanics and Mining Sciences \& Geomechanics Abstracts.15, pp. 237-247. Pergamon Press. Printed in Great Britain.
Brotons,V., Tomás, R., Ivorra, S., Grediaga, A., 2014. Relationship between static and dynamic elastic modulus of calcarenite heated at different temperatures: the San Julian's stone. Bulletin of Engineering Geology Environment, 73 (3), doi 10.1007/s10064-014-0583-y.

Christaras, B., Auger, F., Mosse, E., 1994. Determination of the moduliof elasticity of rocks. Comparison of the ultrasonic velocity and mechanical resonance frequency methods with direct staticmethods. Material Structure, 27:222-228.

Ciccotti, M., Mulargia, F., 2004. Differences between static and dynamic elastic moduli of a typical seismogenic rock. Geophys Journal Int., 157:474-477.

Gue'guen, Y., Palciauskas, V., 1994. Introduction to the physics of rocks. Princeton University Press, New Jersey, p 294.

Deere, D.U., Miller, R.P., 1966. "Engineering Classification And Index Properties For Intact Rock", Tech.Rept. No AFWL-65-116, Air Force Base, New Mexico.

EİE-081, 1992. Ultrasonik yöntemle karot numunelerinin boyuna ve enine elastik dalga hızlarının ölçülmesi ve dinamik elastik parametrelerinin hesaplanması. Elektrik İşleri Etüt İdaresi Genel Müdürlüğü Mühendislik Hizmetleri Normları, Ankara.

EIE-122, 1992. Plaka Yükleme Deneyi Normu. Elektrik İşleri Etüt İdaresi Genel Müdürlüğü Mühendislik Hizmetleri Normları, Ankara.

EIEE-124, 1992. Oyo 200 Dilatometre Deneyi Normu. Elektrik İşleri Etüt İdaresi Genel Müdürlüğü Mühendislik Hizmetleri Normları, Ankara.

Galera, M.J., Alvarez, M., Bieniawski, Z.T., 2005. Evaluation of the deformation modulus of rock masses: comparison of the pressuremeter and dilatometer tests with RMR prediction. ISP5PRESSIO International Symposium.

Hoek, E., Diederichs, M.S., 2006. Empirical estimation of rock mass modulus. International Journal of Rock Mechanics \& Mining Sciences, 43. 203-215. 
Kayabaşı

Devlet Su İșleri Genel Müdürlüğü, http://www.dsi. gov.tr/projeler, (Ziyaret Tarihi 25 Mart 2019).

Goodman, R.E., 1989. Introduction to rock mechanics, 2nd ed., Wiley, New York, 562 p.

ISRM, 1978. ISRM suggested methods for determining the uniaxial compressive strength and deformability of rock materials. International Journal of Rock Mechanics and Mining Sciences and Geomechanics Abstracts, 16,135-140.

ISRM, 1981. ISRM Suggested Methods: Rock Characterization, Testing and Monitoring. E.T. Brown (ed.), Pergamon Press, London, 211 pp.

ISRM, 1998. Suggested methods for seismic testing within and between boreholes. InternationalJournal of Rock Mechanics and Mining Sciences and Geomechanics Abstracts, 25: 447-472.

Kaya, A., Kayabaşı A., 1992. Aşağı Çoruh Havzası Deriner Baraji Elastmeter 200 Deney Sonuç raporu. EİEİ Genel Müdürlüğü. Kaya ve Zemin Mekaniği Şubesi Müdürlüğü (Basılmamış).

Kaya, A., Kayabaşı A., 1998. Ermenek HES Santral Yeri Dilatometre Deney Sonuç raporu. Jeoloji ve Sondaj Dairesi Başkanlığı, Kaya ve Zemin Mekaniği Şubesi Müdürlüğü, EİEI Genel Müdürlüğü, Ankara.

Kujundzíc, B., Grujíc, N., 1966. Correlation between static and dynamic investigations of rock mass "in situ". Proceedings of 1st ISRM Congress, Lisbon. 1: 565-570. LNEC.
Kulhawy, F. H., Goodman, R., 1980. Design of foundations on discontinuous rock. Proc. Int. Conf. Struct. Found. Rock. Ed. Balkema, 209-220.

Martinez-Martinez, J., Benavente, D., Garci'a-delCura, M.A., 2012. Comparison of the static and dynamic elastic modulus in carbonate rocks. Bulletin of Engineering Geology and the Environment, 71: 263-268.

Munır, K., 2006. Development of correlation between rock classification system and modulus of deformation. PhD Thesis-Civil-02, Department of Civil Engineering University of Engineering And Technology, Lahore-PAKISTAN.

Narin, O., Ceylan, O., Uysal, B., 1986. Aşşağı Çoruh Havzas1 Deriner Baraj Yeri Hidrolik Kriko Yükleme Deneyleri Elastisite Raporu. EİEI Genel Müdürlüğü, Yayın No:86-65. Ankara.

Palmstrom, A., Singh, R., 2001. The deformation modulus of rock masses - comparisons between in situ tests and indirect estimates. Tunnelling and Underground Space Technology, Vol. 16, No. 3, pp. 115 - 131 .

Wyllie, D. C., 1992. Foundations on Rock. Principal, Golder Associates, consulting Engineers Vancouver, Canada. 